\title{
Thermodynamic and ecological preselection of synthetic fuel intermediates from biogas at farm sites
}

\author{
Ralf Peters ${ }^{1^{*}}$ (D), Maximilian Decker ${ }^{1}$, Lea Eggemann², Steffen Schemme ${ }^{1}$ Felix Schorn', Janos Lucian Breuer ${ }^{1}$, \\ Stefan Weiske ${ }^{1}$, Joachim Pasel $^{1}$, Remzi Can Samsun ${ }^{1}$ and Detlef Stolten ${ }^{3,4}$
}

\begin{abstract}
Background: Synthetic fuels based on renewable hydrogen and $\mathrm{CO}_{2}$ are a currently highly discussed piece of the puzzle to defossilize the transport sector. In this regard, $\mathrm{CO}_{2}$ can play a positive role in shaping a sustainable future. Large potentials are available as a product of biogas production, however occurring in small scales and in thin spatial distributions. This work aims to evaluate suitable synthetic fuel products to be produced at farm sites.

Methods: A thermodynamic analysis to assess the energetic efficiency of synthesis pathways and a qualitative assessment of product handling issues is carried out.

Results: Regarding the technical and safety-related advantages in storage, liquid products are the superior option for fuel production at decentralized sites. Due to the economy of scale, multi-stage synthesis processes lose economic performance with rising complexity. A method was shown which covers a principle sketch of all necessary reaction, separation steps, and all compression and heat exchanger units. The figures showed that methanol and butanol are the most suitable candidates in contrast to $\mathrm{OME}_{3-5}$ for implementation in existing transportation and fuel systems.

These results were underpin by a Gibbs energy analysis.

Conclusions: As long as safety regulations are met and the farm can guarantee safe storage and transport, farm-site production for all intermediates can be realized technically. Ultimately, this work points out that the process must be kept as simple as possible, favoring methanol production at farm site and its further processing to more complicated fuels in large units for several fuel pathways.
\end{abstract}

Keywords: Power-to-fuel, Bio gas processing, Thermodynamic analysis, Liquid fuel intermediates

\section{Introduction}

The campaign against anthropogenic climate change faces society with the challenge of fully defossilizing the energy system [93], including not only power generation, but also the transportation, heat supply, agricultural, and industrial sectors. Technologies that use renewably produced power in other sectors are referred to as power-to- $x$. Among these concepts, power-to-fuel describes a concept whereby power is utilized to produce substances that can be used as alternative fuels in combustion engines for road

\footnotetext{
* Correspondence: ra.peters@fz-juelich.de

${ }^{1}$ Forschungszentrum Jülich $\mathrm{GmbH}$, Institute for Energy and Climate Research, IEK-14: Institute of Electrochemical Process Engineering, 52425 Jülich, Germany Full list of author information is available at the end of the article
}

transport. As these fuels are produced synthetically, their chemical structure is not restricted to a natural distribution, as it is the case with crude oil. When choosing a synthesis product for use as a transport fuel, the following characteristics should be taken into account:

- Efficiency and economy of the production process

- Combustion characteristics inside the engine

- Compatibility with current handling systems (stationary infrastructure and mobile storage)

- Ecological aspects (e.g., toxicity, safety, or greenhouse gas potential)

Schemme et al. suggest arranging the possible synthetic transport fuels into the following subgroups [76]: 
- Alkanes by Fischer-Tropsch reactions

- Hydrocarbons by oligomerization

- Alcohols

- Ethers

While all types of fuels exhibit different physical characteristics, all have in common that they can be produced from the two-feed chemicals of hydrogen and carbon dioxide within the power-to-fuel approach. Both substances must be obtained in a sustainable manner, so that the resulting synthetic fuels can contribute to defossilization. Hydrogen can be produced via water electrolysis using renewable power sources such as wind, solar, or hydro [22]. $\mathrm{CO}_{2}$ can be obtained from non-fossil sources, such as the process emissions of industrial plants [6], biomass [88], or even direct air capture [35].

The use of decentralized sources of carbon dioxide and hydrogen is of great importance in a future energy system. Synthesis, storage, and transport are central questions when selecting suitable substances that can be produced on-site and then transported away using a suitable infrastructure. First, it must be clarified whether fuels from biomass and hydrogen can potentially make a significant contribution to the energy transition. In the selection, the basic design of the synthesis and thermodynamic analyses, such as process design, is decisive. The handling of chemicals and gases is of great importance on a farm. Therefore, the socio-economic aspects of the preselected fuels are closely examined.

\section{Potential of fuels from biomass}

Numerous studies have estimated global biomass potential. Offermann et al. analyzed and summarized 19 studies [65]. According to their literature review, the global potential was found to range between 0 and $1550 \mathrm{EJ} / \mathrm{a}$ for the year 2050. Within their analysis method, the concluded potentials are divided into 200-600 EJ /a for energy plants and 62-325 EJ/a for residual materials [7]. The global biomass potentials are very unequally distributed. Asia, Africa, and South America hold the highest potential, while Europe, North America, and the Pacific only contribute a small extent to the overall potential. To classify these figures, only 49 EJ of the total energy demand of 503 EJ, i.e., 9.74\%, were based on biomass in 2007. The share of bio energy has not changed from 2007 to 2016 while the total energy demand worldwide increased about $15 \%$. In 2016, 56 EJ of bio energy contributed to a total demand of 576 EJ, i.e., 9.77\% [41]. Estimates vary widely, as there are many uncertainties regarding the use of uncultivated land (0-580 Mha) and congestion externalities. Berndes et al. drew on 17 studies for their analysis [5]. They estimated global biomass potentials to range between 100 and $400 \mathrm{EJ} / \mathrm{a}$, from which 50-240 EJ/a was based on energy crops. The main biomass source is wood. The potentials were estimated at a maximum of $115 \mathrm{EJ} / \mathrm{a}$ in 2050, also with a focus of production in Asia, Africa, and South America. Parrika also estimates the potential at $100 \mathrm{EJ} / \mathrm{a}$, with about 41.6 EJ/a for wood [66]. A share of $40 \mathrm{EJ} / \mathrm{a}$ of global biomass was found to be used for energy. The focus is also in Asia, with $60 \%$. In Europe, the potential for energy from biomass is $8.9 \mathrm{EJ} / \mathrm{a}$, with a breakdown into $4 \mathrm{EJ} / \mathrm{a}$ wood, $2.6 \mathrm{EJ} / \mathrm{a}$ energy crops, and $1.6 \mathrm{EJ} / \mathrm{a}$ straw and accounting for approximately $10 \%$ of the global potential.

Kaltschmitt et al. assess initially biomass potentials and subsequently, the prospects for usage [47]. They break down potentials into 12 segments in which gas was not analyzed. High potential (almost $75 \%$ ) was identified for wastes and residues, i.e., in the segments of excrement and litter ( 67\%), harvest residues, waste from trade and industry, and organic municipal residues. Regional differences presumably play a large role here. Without the cultivation of energy crops, Kaltschmitt et al. expect a potential of 960-1050 PJ/a, representing 741-770 PJ/a for thermochemical conversion and 219$280 \mathrm{PJ} / \mathrm{a}$ for biochemical conversion [47]. The resulting final energy potentials for fuels are 71-145 PJ/a available as straw-like waste and 225-394 PJ/a as woody waste. An additional 111-162 PJ/a also arises from the biochemical conversion of waste where methane is the end product. In addition to the potential of biomass waste, Kaltschmitt et al. estimated a land availability of 2 mil ha for energy crops in Germany [47]. In combination with the cultivation of short-rotation coppice, e.g., poplar trees, a harvest rate of $12 \mathrm{t} / \mathrm{ha} / \mathrm{a}$ can be achieved leading to 24 Mt wood/ a. Putting the focus on Miscanthus grass, Christian et al. reported an average yield of about $12.8 \mathrm{t} / \mathrm{ha}[15]$.

A further focus can be set on wood and straw gasification as part of the 12 segments defined in Kaltschmitt et al. [47]. According to a process analysis from Grube et al., the CHOREN/FT process results in a $200 \mathrm{~kg} / \mathrm{h}$ fuel mix from $1 \mathrm{t} / \mathrm{h}$ wood with a focus on diesel and kerosene (about $154 \mathrm{~kg} / \mathrm{h}$ ) [37]. The resulting final energy potential for this process chain is $206 \mathrm{PJ} / \mathrm{a}$, corresponding to $4.8 \mathrm{Mt}$ fuel/a. Kerdoncuff calculated in 2008 for the evaluation of the BioLiq-process with a fuel production rate of $60-70 \mathrm{~kg} / \mathrm{h}$ out of $1 \mathrm{t} / \mathrm{h}$ of residual wood and $115 \mathrm{~kg} / \mathrm{h}$ fuel out of $1 \mathrm{t} / \mathrm{h}$ of residual straw [48]. Trippe worked with a rate of $106 \mathrm{~kg} / \mathrm{h}$ out of $1 \mathrm{t} / \mathrm{h}$ residual straw for his techno-economic analysis [87]. According to the data of Dahmen and Sauer, the fuel production rate could be increased to $133 \mathrm{~kg} / \mathrm{h}$ out of $1 \mathrm{t} / \mathrm{h}$ residual straw [16]. In turn, combining 2 mio. ha with $12 \mathrm{t}$ biomass /ha and those conversion rates lead to fuel energy potential between 140 and 205 PJ/a corresponding to 3.2-4.8 Mt fuel/a in good accordance with the values of Kaltschmitt et al. [47]. 
The addition of hydrogen can improve the efficiency of fuel production from biomass. Dietrich et al. [19] combined the biofuel processing with electrofuel production from renewable hydrogen and $\mathrm{CO}_{2}$ within their cost analysis. In comparison, Gale et al. reported a value of $90.6 \mathrm{Mt} / \mathrm{a} \mathrm{CO}_{2}$ emissions from bioenergy and fermentation which can be taken into account [30]. This amount can be supplemented by electrofuels with $\mathrm{CO}_{2}$ from industrial sources. Gale et al. listed numerous industrial $\mathrm{CO}_{2}$ sources with average emissions of between 0.58 and 3.94 $\mathrm{Mt} \mathrm{CO}_{2}$ per anno and per source, such as fossil-based power plants (mostly coal), cement production, refineries, integrated steel mills, and petrochemical processes for ethylene and ammonia synthesis. Currently, steel makers are considering the reduction of iron by hydrogen while the cement industry still relies on limestone. Furthermore, Billig et al. identified cement industry and biomass fermentation as future $\mathrm{CO}_{2}$ feedstocks for electrofuels [6]. Billig et al. also analyzed the potential of $5.2 \mathrm{Mt} \mathrm{CH}_{4}$ and $11.9 \mathrm{Mt} \mathrm{CO}_{2}$ from about 9000 fermentation plants, including biogas upgrading in Germany, leading to 260 PJ/a. An additional quantity of

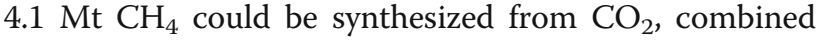
with 2.2 Mt hydrogen from wind. The feedstock for such plants will be shifted from energy crops to residual biomass, such as straw and dry and liquid manure and waste streams. Finally, the potential of methane from fermentation could reach 9.3 $\mathrm{Mt} \mathrm{CH}_{4}$, directly and indirectly via $\mathrm{CO}_{2}$ methanation, corresponding to $465 \mathrm{PJ} / \mathrm{a}$ in 2050. Billig et al. reported a slightly decreasing $\mathrm{CO}_{2}$ foot print in the cement industry, with $15.1 \mathrm{Mt} / \mathrm{a}$ in 2050, resulting in $5.5 \mathrm{Mt} \mathrm{CH}_{4} / \mathrm{a}$ [6]. Finally, the $\mathrm{CH}_{4}$ potential consists of $5.4 \mathrm{Mt} / \mathrm{a}$ of bio-methane and, additionally, 9.6 Mt/a via $\mathrm{CO}_{2}$ methanation from $\mathrm{CO}_{2}$ separated from the cement industry and biogas. The $\mathrm{H}_{2}$ demand for both $\mathrm{CO}_{2}$ sources amounts to $4.8 \mathrm{Mt} / \mathrm{a}$ in 2050. The total energy of methane adds up to $750 \mathrm{PJ} / \mathrm{a}$.

In order to compare these values, the demand for middle distillates in Europe amounted to 256.7 million t/a diesel and 40.4 million t/a kerosene [29] in 2016. This equates to annual energy volumes of 8.6 EJ for diesel and 2.2 EJ kerosene. In Germany, 37.9 Mt of diesel and 9.2 Mt of jet fuel were consumed in 2016, corresponding to $1630 \mathrm{PJ} / \mathrm{a}$ diesel and nearly $400 \mathrm{PJ} / \mathrm{a}$ jet fuel [59]. The analyzed amount of potential biogas in Germany-from fermentation and the power-to-gas route of the byproduct $\mathrm{CO}_{2}-$ could meet a large share of today's diesel demand if compressed natural gas or liquefied natural gas can be introduced in the mobility sector as widespread fuels.

Unfortunately, the economic aspects of synthetic methane offer poor prospects for widespread market introduction. Different research groups have published techno-economic analyses for power-to-gas and biogas synthesis plants [31, 32, 36, 38, 60, 61]. Gassner and Maréchal designed the operation of their methanation unit to achieve $1.47 € / \mathrm{kg}[31,32]$. Meanwhile, Peters et al. analyzed costs of $3.8 € / \mathrm{kg}$ for $\mathrm{CO}_{2}$ from fermentation and $\mathrm{H}_{2}$ from wind energy via electrolysis and 1.8 $€ / \mathrm{kg}$ for $\mathrm{CO}_{2}$ and $\mathrm{H}_{2}$ from biomass [70]. Brynolf et al. analyzed several studies in a review paper and noted methanation costs by anaerobic digestion in a broad range of $0.13-2.5 € / \mathrm{kg}$ and $1-1.2 € / \mathrm{kg}$ by means of the gasification of lignocellulose [8]. Electricity and/or hydrogen cost assumptions play a crucial role. Tremel et al. reported specific costs of about $0.169 € / \mathrm{kWh}$, corresponding to $2.34 € / \mathrm{kg}$ at hydrogen costs of $3 € / \mathrm{kg}[86]$, while Peters et al. assumed $5.5 € / \mathrm{kg}$ [70]. The electricity price of $14 \$ / G J$, taken from Hannula leads to an extremely low hydrogen cost of about $2.7 € / \mathrm{kg} \mathrm{H}_{2}$ for an electrolyzer efficiency of $62 \%$ [38]. Hannula reported thermochemical methanation costs of about $0.9 € / \mathrm{kg}$ and $1.85 € / \mathrm{kg}$ for the electrochemical pathway. Approximating these different assumptions led to the conclusion that the cost data fits very well to the gasification and power-to-gas routes. In order to classify these costs, the external gas price without taxes at the German border amounts to $2 €$-cent/kWh, corresponding to a value of $0.25 € / \mathrm{kg}$ of natural gas. Finally, there is a large hurdle to switch from fossil fuels to bio-methane or power-to-gas.

Otherwise, the ecological aspects indicate an extremely positive outlook for bio-methane from liquid manure fermentation. As analyzed by Peters et al., the $\mathrm{CO}_{2}$ footprint for the fossil natural gas used in automotive applications increases from 54.8 to $70.2 \mathrm{~g} \mathrm{CO}_{2} / \mathrm{MJ}_{\mathrm{f}}$ due to methane slip resulting from exploration, transport, storage, and usage in transportation [70]. Renewable pathways such as municipal waste gasification result in $12.1 \mathrm{~g} \mathrm{CO}_{2} / \mathrm{MJ}_{\mathrm{f}}$. The fermentation of liquid manure gets high credit if it is not distributed on cultivated land. In combination with hydrogen from wind energy via electrolysis, $\mathrm{CO}_{2}$ methanation can achieve a credit of $-78.1 \mathrm{~g} \mathrm{CO}_{2} / \mathrm{MJ}_{\mathrm{f}}$ for the entire chain. Todays a feedstock mixture of liquid manure, biomass waste and silage is used for fermentation leading to a mixed value for the $\mathrm{CO}_{2}$ footprint. For a small $75 \mathrm{~kW}$ unit, a mix of $3300 \mathrm{t}$ of cattle manure and $790 \mathrm{t}$ corn silage is proposed on a yearly base [91]. For a larger $500 \mathrm{~kW}_{\mathrm{e}}$ unit, the relation is shifted toward silage of different sources and cattle manure, i.e., 8700 and $2200 \mathrm{t}$ on a yearly base, respectively.

A huge advantage of bio fermentation plants is that they already exist, while large-scale gasification for residual wood and straw has not yet left the pilot plant stage. It makes sense to implement these small units into a future renewable energy system. In regard of the negative impact of fertilization with manure on the soil, it makes sense to increase the number of biogas plants or 
to build-up new larger facilities. Today, only $30 \%$ of the manure volume was used in fermentation $[3,89]$. An amount of $200 \mathrm{~m}^{3}$ liquid manure from $300 \mathrm{~m}^{3}$ in total is used for fertilization. If the share of biogasification should be increased up to $60 \%$, two related issues come up: (a) Is there a need to increase the amount of silage in parallel or could the mixture be changed towards more manure? (b) What should be made with the higher amount of biogas? In 2016, about 9000 fermentation plants could be found in Germany; only less than 200 offered a biogas upgrade to bio-methane and grid connection $[3,6,24,25,89,91]$. In regard to storage and transport, a liquid fuel is preferred. A techno-economic analysis of methanation is already performed by Peters et al. [70]. It was shown that the economic prospects of a widespread usage in relation to today's natural gas cost are very difficult for an adequate market introduction. The questions that arise, however, include what else can be synthesized from $\mathrm{CH}_{4} / \mathrm{CO}_{2}$-mixtures at reasonable costs? Which plant configuration is best to implement on farm sites?

Decker et al. present a design of a small-scale plant for the production of synthetic fuels, including a transient simulation of the operation and a subsequent economic evaluation of the designed system [18]. Taking the transient nature of the system into account is crucial for its design, as the allocation of both hydrogen and carbon dioxide from biogas is discontinuous. The fuel production pathways that have been evaluated were FischerTropsch and methanol synthesis due to the lower number of process steps compared to other synthesis products $[74,75]$ and, therefore, favorable economic performances [8]. For a broader implementation, a suitable fuel with high energy density should be chosen that can easily be transported to a central refinement plant for subsequent upgrading steps up to a standardized transport fuel. Alternatively, an intermediate with the same properties can be produced on a farm site and then transported to a central site where the final fuel can be produced.

This paper covers the selection process of the different fuel types in detail. Technical aspects like production, utilization, and handling are evaluated by means of a thermodynamic analysis. Based on this analysis, the ecological and economic aspects will be evaluated to yield a set of recommendations of suitable synthetic transport fuels produced in decentralized plants with $\mathrm{CO}_{2}$ supply from biogas plants.

\section{Basic fuel synthesis design}

This section's basic fuel synthesis design discusses aspects of hydrogen and carbon dioxide provision. Hydrogen will be produced via electrolysis using renewable electricity from wind farms. Carbon dioxide can be separated from biogas plants after the fermentation of biomass. Bio waste and (liquid) manure should preferably be used due to the recent trend in biogas subsidization of waste products in Germany and the debate about food versus fuel.

An alternative could be the implementation routes of bio catalytic activation. A coupling of the power-to-fuel concept directly with such pathways might be useful but is still an open research field for further studies in future.

\section{Hydrogen production from wind turbines via electrolysis}

Given the fluctuating nature of wind and solar energy, hydrogen production based on those renewable energy sources follows a highly dynamic provision profile. Electrolysis systems can handle this fluctuating income of electricity sufficiently, but subsequent chemical production processes require constant raw material flows for synthesis reactions. Therefore, hydrogen storage systems must be implemented. The upper part of Fig. 1 shows a general process scheme for hydrogen production and storage from wind energy via electrolysis or from the electric grid. Wind power data were modeled according to data from Decker et al. for the different locations, here shown for Cuxhaven in Germany on the basis of weather data from 2013 [18]. Wind data from Cuxhaven offers about 2818 full load hours, representing a good location for electricity production. The lower part of Fig. 1 shows modeled time-dependent values for electric power generation and hydrogen production as a lower heating value (LHV) for the time period 31.5.-6.6.2013 and underpins the concept of power-to-X solutions: At the beginning of this selected week, some peaks with high electricity output from the wind turbine occur, achieving values of over $3.5 \mathrm{MW}_{\mathrm{e}}$ for short time periods. The third day $(3648-3672 \mathrm{~h})$ is the best day of this week, with values between 2.5 and $4.1 \mathrm{MW}_{\mathrm{e}}$, but mostly above 3.5 $\mathrm{MW}_{\mathrm{e}}$. At the end of the week, only short periods with 2 $\mathrm{MW}_{\mathrm{e}}$ were achievable. Power-to-x offers different concepts for the management of such complex energy systems, so that the electricity generated from renewables can be used as a reliable pillar in a stable and sustainable energy system, despite its fluctuating character.

The concept of Decker et al. applies PEM electrolysis for hydrogen production in four different operation modes A-D (see the upper part of Fig. 1) [17, 18].

\section{Mode A}

Mode A constantly uses electricity from the grid with a mixed share of renewables and fossil-based primary energy. The blue electric line of mode A in Fig. 1 is chain dotted, i.e., “--.-.-.," Consequently, $\mathrm{CO}_{2}$ reduction targets are only achievable if the share of renewables for electricity production is high and corresponding storage technologies for re-electrification are implemented. 


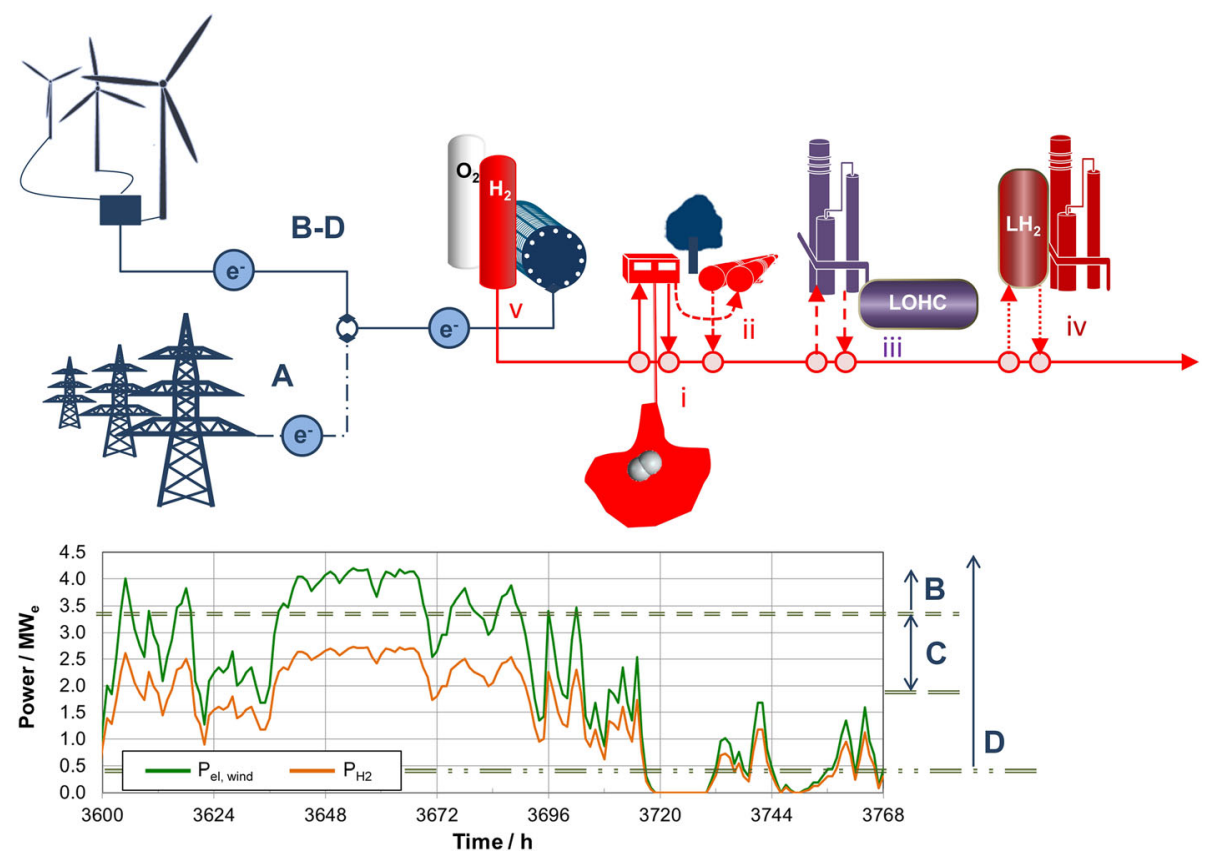

Fig. 1 General process scheme for hydrogen production and storage from wind energy via electrolysis or from the electric grid. Wind power data were modeled according to data from Decker et al. for different locations, here: Cuxhaven in Germany, based on weather data from 2013 [18]. A Electricity from the grid; B-D electricity from the wind park: only surplus of electricity (B), the load regime for electrolysis between the base load of the grid and curtailment at an upper limit (C) and full spectrum to high electricity generation with curtailment at a lower limit and (D) as off-grid electricity supply

Modes B, C, and D represent the renewable modes and are therefore combined in the general process scheme. The differences between the different modes are explained using the example wind power data presented in the lower part of Fig. 1.

\section{Mode B}

Mode B uses only those peaks in the electric grid that occur if the integral renewable electricity is higher than the current demand. Presently, this situation seldom appears with today's medium share of renewables. The electric line of modes B$\mathrm{D}$ are drawn continuously in blue in Fig. 1.

\section{Mode C}

Mode $\mathrm{C}$ assumes a well-settled network of wind parks, electrolyzers, hydrogen storage systems, and hydrogen supply by pipeline in Germany for 2050, according to the work of [71]. In such a system, wind turbines produce electricity for the currently occurring demand from the electric grid and above (range $\mathrm{C}$ in Fig. 1) for hydrogen production via electrolysis. A curtailment of all of the wind energy was implemented to limit investments in light of a techno-economic assessment.

\section{Mode D}

Mode D foresees the small-scale usage of wind energy and an adapted hydrogen storage concept with a curtailment at low loads. Different hydrogen storage concepts can be considered: salt caverns locally used (i); salt caverns inclusive of $\mathrm{H}_{2}$ pipelines for cross-regional transport (ii); liquid organic hydrogen carriers (LOHCs) [85] (iii); liquid hydrogen storage (iv); and, finally, gaseous hydrogen storage (v). In this paper, the small-scale operational mode (D) is combined with the storage option in salt caverns (i) in accordance with the recommendation of Decker et al. [17, 18]. In the following, this setup will be referred to as "D-i."

\section{$\mathrm{CO}_{2}$ capture from biogas plants}

Currently, biogas can be directly burned in a stationary internal combustion engine that is mechanically connected to an electric generator and heat supply for stables and other facilities. If methane is fed into the natural gas grid, $\mathrm{CO}_{2}$ must first be separated from the biogas and then the gas has to be upgraded to natural gas quality.

Szarka et al. reported on a flexible, demand-oriented power supply by means of bio energy [84]. More detailed information on the dynamic operation mode of fermentation can be found in Jacobi and Thrommler [45]. The process of gas production can be controlled among other factors by the feeding times of the biogas plant. Three different substrates lead to fast, medium, or slow digestion and a corresponding time from feeding to manure origination. Figure 2 shows the general process 


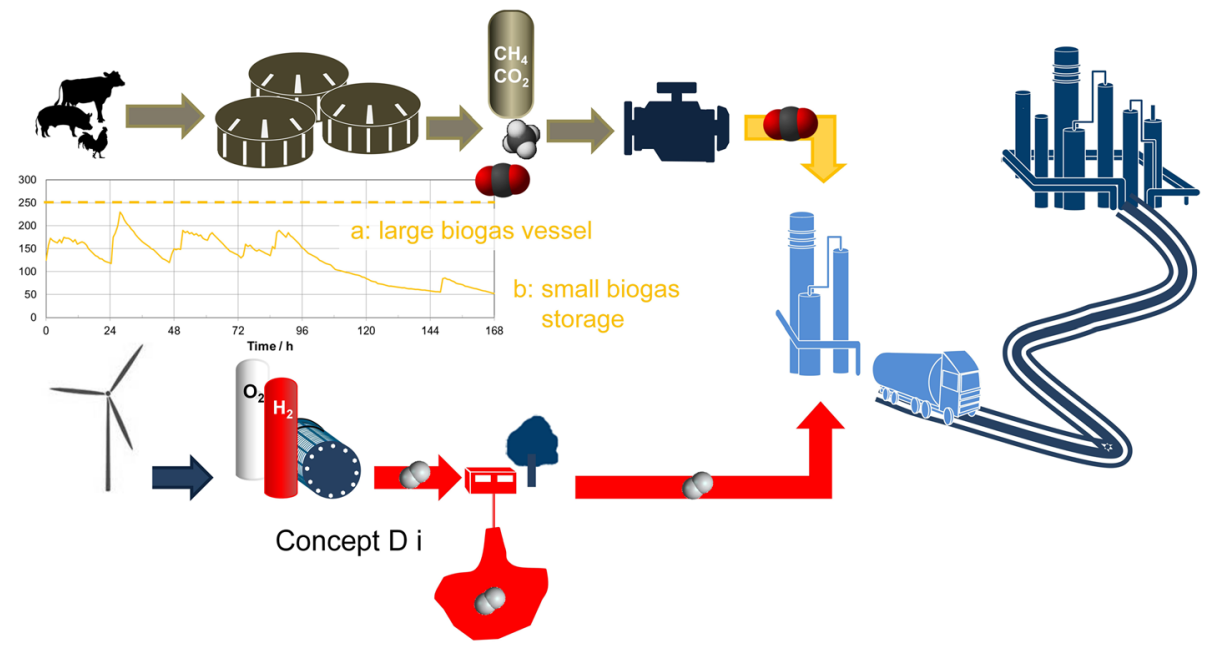

Fig. 2 General process scheme for $\mathrm{CO}_{2}$ provision from liquid manure by biomass fermentation. Dynamic profile for biogas generation for one week according to [45]

scheme for $\mathrm{CO}_{2}$ provision from liquid manure from biomass fermentation. The dynamic profile for biogas generation for 1 week was sketched in accordance to Jacobi and Thrommler [45]. A constant biogas provision can be guaranteed by implementing a large vessel, while a flexible operation mode allows for a smaller biogas storage vessel. Recently, biogas plants tend more toward a flexible operation; however, the concept that is proposed in this paper prefers constant biogas provision. In combination with the D-i concept for hydrogen production, constant fuel production can be achieved. The local fuel synthesis ideally produces a liquid intermediate that can be further processed at a central fuel production facility. The combination of wind energy and fermentation allows for greater flexibility in system design that is partly caused by different pre-processing units.

Figure 3 shows the general process scheme for using methane and carbon dioxide from biogas for synthetic fuel production. Carbon dioxide can be separated in front of the combined heat and power plant (CHP) to get pure $\mathrm{CO}_{2}$ for the synthesis process. The option is indicated by a continuous line in Fig. 3. The first system draft combines the separated $\mathrm{CO}_{2}$ with renewable hydrogen that is generated by means of electrolysis using electricity from the wind park to form a fuel according to Eq. (1). Water must also be provided, and partly can be recovered from subsequent process steps such as reverse water gas shift and after appropriate cleaning. A second option is to separate $\mathrm{CO}_{2}$ behind the internal combustion engine (ICE) as post-combustion, whereby the specific effort is more caused by dilution with nitrogen, excess air, and water. This path is indicated by a dotted line.
The mixture of hydrogen and carbon dioxide is conducted in a synthesis unit (a) that is able to convert $\mathrm{CO}_{2}$ and $\mathrm{H}_{2}$ into certain kinds of fuels, $\mathrm{X}$.

$$
\begin{aligned}
& \mathrm{n} \mathrm{CO}_{2}+\left(\frac{\mathrm{m}}{2}+2 \mathrm{n}-\mathrm{l}\right) \mathrm{H}_{2} \leftrightarrow C_{n} \mathrm{H}_{m} \mathrm{O}_{l}+(2 \mathrm{n}-\mathrm{l}) \mathrm{H}_{2} \mathrm{O} \\
& \Delta_{\mathrm{R}} \mathrm{H}^{\mathrm{o}}<0 \mathrm{~kJ} / \mathrm{mol}
\end{aligned}
$$

Fischer-Tropsch synthesis requires carbon monoxide as an educt:

$$
\begin{aligned}
& \mathrm{n} \mathrm{CO}+\left(\frac{\mathrm{m}}{2}+\mathrm{n}-\mathrm{l}\right) \mathrm{H}_{2} \leftrightarrow C_{n} \mathrm{H}_{m} \mathrm{O}_{l}+(\mathrm{n}-\mathrm{l}) \mathrm{H}_{2} \mathrm{O} \\
& \Delta_{\mathrm{R}} \mathrm{H}^{\mathrm{o}}<0 \mathrm{~kJ} / \mathrm{mol}
\end{aligned}
$$

Therefore, a reverse water-gas shift reactor must be implemented in front of a synthesis unit B, see Eq. (3). Water must be separated in front of synthesis unit (b).

$$
\mathrm{CO}_{2}+\mathrm{H}_{2} \leftrightarrow \mathrm{CO}+\mathrm{H}_{2} \mathrm{O} \Delta_{\mathrm{R}} \mathrm{H}^{\mathrm{o}}=41.17 \mathrm{~kJ} / \mathrm{mol}
$$

A further option is direct reforming of methane with carbon dioxide according to Eq. (4) (dry reforming).

$$
\mathrm{CO}_{2}+\mathrm{CH}_{4} \leftrightarrow 2 \mathrm{CO}+2 \mathrm{H}_{2} \Delta_{\mathrm{R}} \mathrm{H}^{\mathrm{o}}=246.97 \mathrm{~kJ} / \mathrm{mol}
$$

During direct reforming of methane, no water will be formed. Neglecting the occurrence of the water-gas shift reaction which occurs in reality it is theoretically possible to avoid the implantation of a water condenser.

In the next section, the thermodynamic conditions will be discussed for reactions (1)-(4). The following research questions arise from the considerations outlined above: 


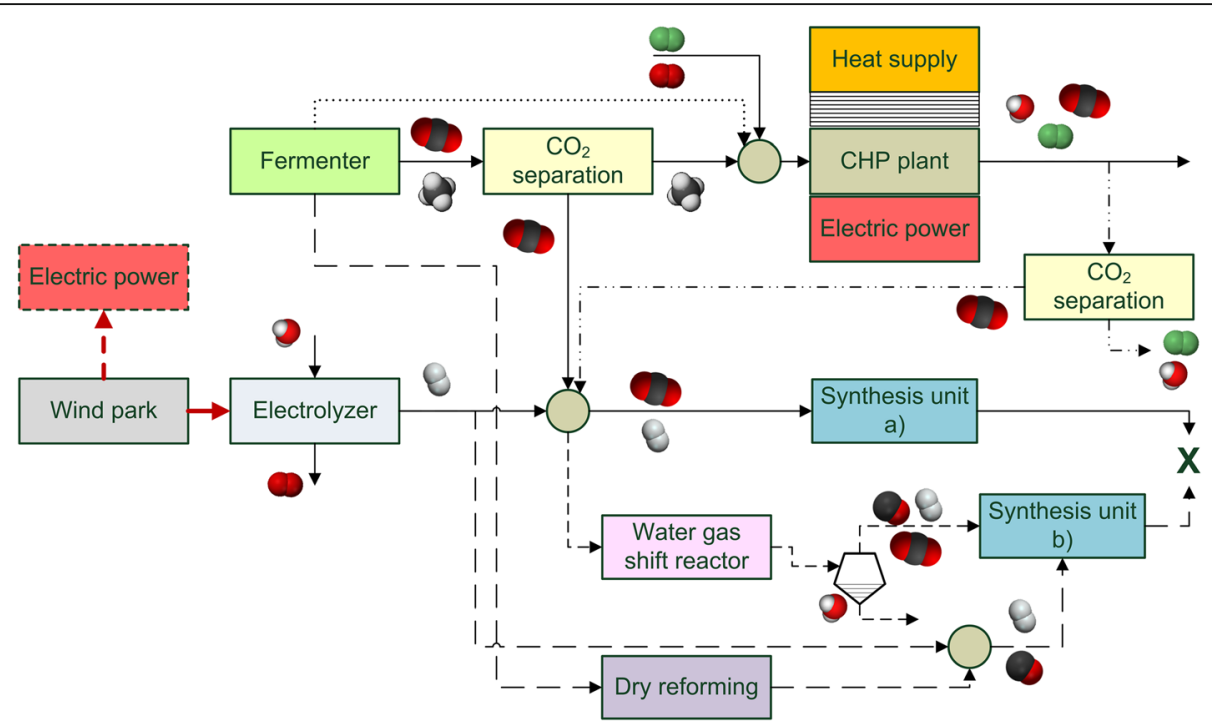

Fig. 3 General process scheme for using methane and carbon dioxide from biogas for synthetic fuel production

- What size of equipment should be installed?

- Which fuel should be preferentially produced?

- What kind of system must be foreseen as decentralized installation?

To answer these questions, general thermodynamic methods, insights from process analysis, basic economic calculations, and socio-economic aspects must be taken into account.

\section{Thermodynamic analysis}

In this section, different thermodynamic analysis methods are compiled to evaluate different process chains for electrofuel production. In the first section, syngas production considers a pre-reaction of hydrogen and carbon dioxide or methane and carbon dioxide in order to form a typical syngas mixture consisting of hydrogen and carbon monoxide. A brief analysis of options for the direct synthesis of electrofuels from hydrogen and carbon dioxide, or from syngas, follows. Considering the claim of a product or intermediate with a high power density prefers the selection of a liquid. Fischer-Tropsch synthesis primarily leads to alkanes with chain lengths up to waxes. Additionally, the process for achieving diesel fuel is fairly complex.

The next section applies a simplified Gibbs energy analysis for the production of octanol and $\mathrm{OME}_{3-5}$ mixtures as optional substitutes for diesel fuel. Subsequently, a process analysis evaluates the complexity of different process chains. Finally, selected electrofuels will be considered for the optimization of synthesis routes. On the basis of this evaluation procedure, selected electrofuels pass to the next evaluation step, i.e., a socio-economic analysis.

\section{Syngas production}

The operation parameters for syngas production by reverse water-gas shift reaction, Eq. (3), and dry reforming, Eq. (4), were determined by chemical equilibrium calculations. At high pressures, the ideal gas state relation must be replaced by an equation that describes the real gas behavior. An overview of the development of such equations was given in 1993 by Soave [81]. In this paper, a modification of the original Redlich-Kwong equation is applied for the thermodynamic gas phase description already made by Soave in 1972 [82]. This equation of state is termed in the following sections as the Soave-Redlich-Kwong (SRK) equation of the state or equation of state (EOS) SRK.

Figure 4 shows the chemical equilibrium of the reverse water-gas shift reaction (rWGS) at 1 bar. It is also important to note that a conversion higher than $80 \%$ is only achieved at temperatures higher than $1173 \mathrm{~K}$. Unconverted $\mathrm{H}_{2} / \mathrm{CO}_{2}$ can be recycled but the recycle loop flow increases strongly with decreasing conversion. For the synthesis of methane, an educt mixture of $\mathrm{H}_{2}: \mathrm{CO}$ of 3:1 is required, while for butane this ratio amounts to 9:4. The chemical equilibrium at $1473 \mathrm{~K}$ for an educt mixture of $\mathrm{H}_{2} / \mathrm{CO}_{2}=4$ offers a product mixture of $75.6 \% \mathrm{H}_{2}$ and $21.6 \% \mathrm{CO}$ in a dry state, i.e., $\mathrm{H}_{2} /$ $\mathrm{CO}=3.46$. An educt mixture of $\mathrm{H}_{2} / \mathrm{CO}_{2}=3$ leads to a product mixture of $\mathrm{H}_{2} / \mathrm{CO}=2.45$. In order to avoid carbon deposits, it is practical to give some hydrogen in excess.

Figure 5 shows the chemical equilibrium of dry reforming at 2 bar. An ideal mixture for a gas fermenter is a gas mixture of methane to carbon dioxide of $1: 1$. At temperatures of $1073 \mathrm{~K}$, conversion higher than $80 \%$ will be achieved. The hydrogen to carbon monoxide ratio in the product gas amounts to 1:1. Finally, after the dry reforming, extra hydrogen must be added to this mixture to fulfill the conditions of fuel synthesis. Biogas mostly 


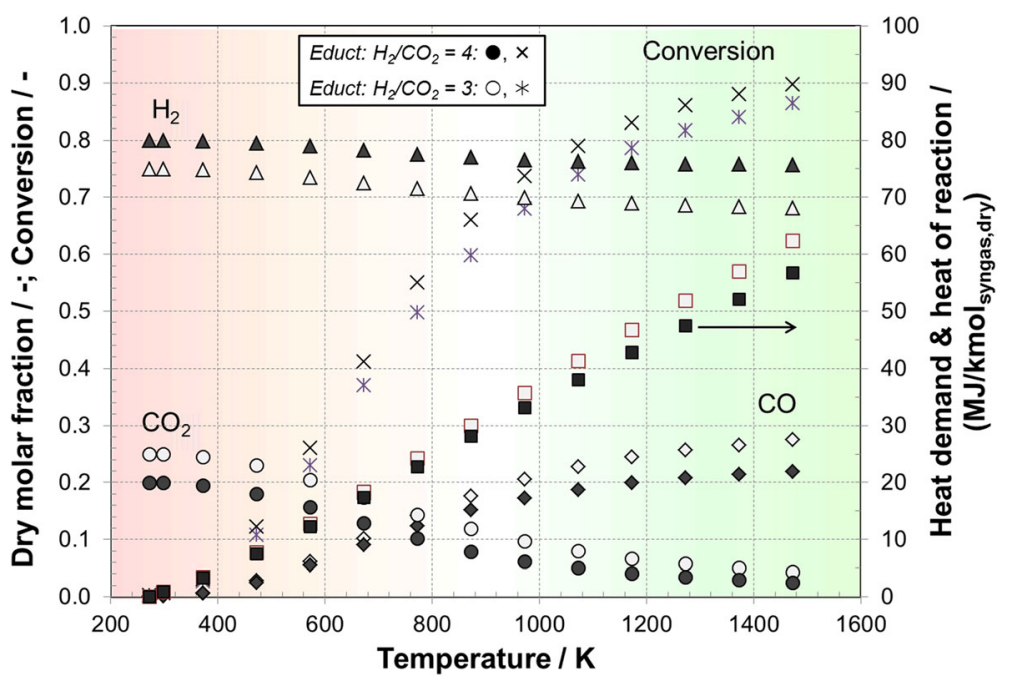

Fig. 4 Chemical equilibrium of reverse water-gas shift reaction at 1 bar for two educt mixtures $\mathrm{H}_{2} / \mathrm{CO}_{2}=4$ and $\mathrm{H}_{2} / \mathrm{CO}_{2}=3$. Red-colored background: low conversion; green colored background: high conversion (goal)

offers a surplus of methane, for example 60\% (Vol.), leading to a ratio of $\mathrm{CH}_{4} / \mathrm{CO}_{2}=1.5$. In such cases, conversion drops to values below $65 \%$. It is important to note that the endothermic heat of reaction for the case of dry reforming is high, with values of about $200 \mathrm{MJ} /$ $\mathrm{kmol}$ syngas related to $40 \mathrm{MJ} / \mathrm{kmol}$ for the reverse water-gas shift reaction, see Fig. 6. For rWGS and dry reforming, educt gases must be heated to above $1000 \mathrm{~K}$, with additional thermal energy supplied under such reaction conditions. The product gas should then be cooled down to the reaction temperature of the synthesis reaction. This allows heat recuperation for preheating the educts. With regard to the goal of GHG emissions reduction, no fossil fuel should be burnt.
In the case of a gas fermenter, a part of the biogas can be used or direct electrical heating using renewable electricity from a wind turbine can guarantee a low- $\mathrm{CO}_{2}$ footprint for the concept. The efficiency of syngas production is defined as the lower heating value of the product gas times the amount of produced gas divided by the sum of the lower heating value of the educt gas, times the educt gas amount and the heat input, as shown in Eq. (5):

$$
\eta_{P T L}=\frac{\dot{m}_{\text {Fuel }} \cdot H_{u, K}}{\frac{\dot{m}_{H 2} \cdot H_{u, H 2}}{\eta_{H 2}}+P_{C O 2}+P_{A}}
$$

This efficiency is high for rWGS, i.e., 96\% and much lower for dry reforming with $57 \%$ due to the high heat

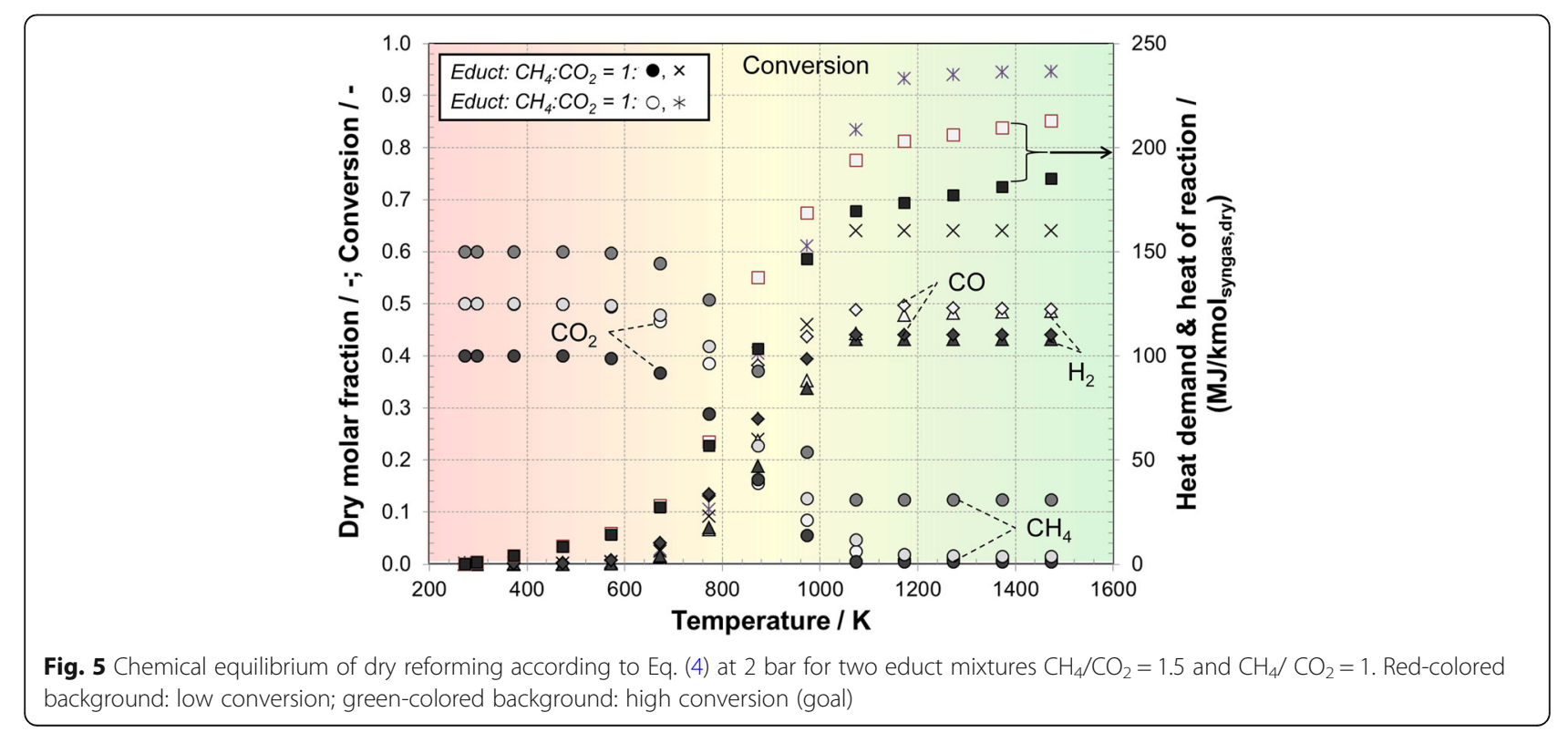



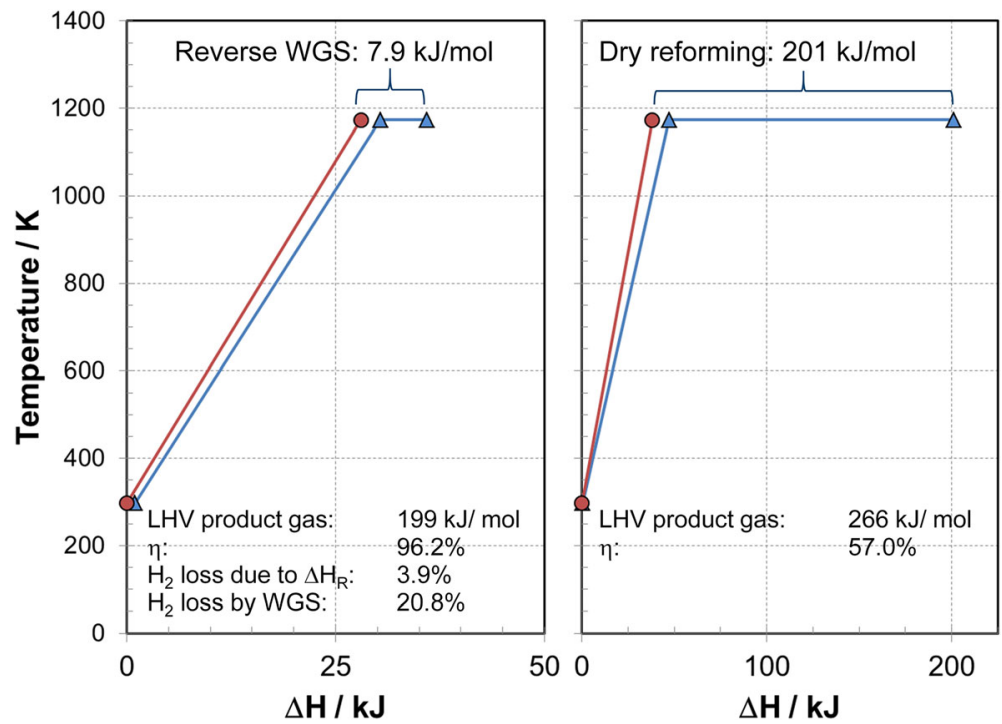

Fig. 6 Comparison of reverse WGS with dry reforming at 2 bar and $1173 \mathrm{~K}$ for the educt mixtures $\mathrm{H}_{2} / \mathrm{CO}_{2}=4$ (left) and $\mathrm{CH}_{4} / \mathrm{CO}_{2}=1$ (right)

of the reaction. The $\mathrm{H}_{2}$ balance of rWGS shows that a high share of $20.8 \%$ is lost by the chemical reaction and only $3.9 \%$ of the hydrogen can be used for the heat supply if this would be taken into account for delivering the heat of reaction of rWGS. Figure 6 visualizes the abovepresented comparison between the two process routes.

From the preceding section, it can be concluded that syngas production for fuel synthesis is favorably performed by the reverse water-gas shift reaction.

\section{Direct synthesis}

A more advantageous option would be the direct synthesis from $\mathrm{CO}_{2}$ and $\mathrm{H}_{2}$. In order to check the capability of realizing direct synthesis, Peters [69] developed a method for methanol, dimethyl ether, and polyoxymethylene dimethyl ether (OME) by applying the equations of state by Soave [82] and Peng and Robinson [67] for real gases at high pressures. A simplified check can be done by assuming ideal gas conditions. At standard conditions, i.e., $p=1.013$ bar and $T=298.15 \mathrm{~K}$, a first impression of the ability of a chemical reaction can be reached. Catalysts demand an individual ignition temperature to catalyze a chemical reaction. Additionally, a pressure increase enhances the chemical reaction if the number of moles decreases during the chemical reaction, according to the principle of Le Chatelier (see Smith and van Ness [80].

The free enthalpy or Gibbs energy $(G)$ is considered a criterion for the spontaneity of a reaction and is negative for any spontaneous chemical reaction [80]. If a reversible reaction is considered, as is the case for fuel synthesis from $\mathrm{CO}_{2}$ and $\mathrm{H}_{2}$, the Gibbs energy can be used as a measure of the chemical equilibrium; see [69]. The total
Gibbs energy $\left(G_{M}\right)$ of a mixture is defined by the sum of the chemical potentials of all participating species $N$ [80].

$$
G_{M}=\sum_{j=1}^{N} n_{j} \mu_{j}
$$

with $G_{\mathrm{T}}$ : [J]; $n_{\mathrm{i}}$ : molar number of species $i[\mathrm{~mol}] ; \mu_{\mathrm{i}}$ : chemical potential of species $i[\mathrm{~J} / \mathrm{mol}]$. Gibbs energy can be calculated for each species by the following:

$$
G_{j}=H_{j}-T S_{j}
$$

The values for enthalpy $H_{\mathrm{j}}$ and entropy $S_{\mathrm{j}}$ were calculated as temperature-dependent expressions by Perry and Green [68]. The resulting Gibbs energy incorporates the stoichiometry of the individual chemical reactions and ideal mixing rules. It is assumed that all chemical reactions would be performed until conversion to the product reached $100 \%$. Restrictions from chemical equilibrium were not considered in the simplified comparison method. Standard temperature and pressure, i.e., $298.15 \mathrm{~K}$ and 1 bar was set for the first step. Two cases were analyzed: (a) complete fuel synthesis from $\mathrm{CO}_{2} / \mathrm{H}_{2}$; and (b) complete fuel synthesis from $\mathrm{CO} / \mathrm{H}_{2}$. This kind of Gibbs energy analysis will be applied to alkanes, ethers, and alcohols of different chain lengths. Figure 7 shows the results of a Gibbs energy analysis for direct synthesis of various fuels from $\mathrm{H}_{2} / \mathrm{CO}_{2}$ and $\mathrm{H}_{2} / \mathrm{CO}$ mixtures at 1 bar. The number of carbon atoms is sketched on the $x$-axis. If the change in Gibbs energy is near zero-as is the case for methanol synthesis-an equilibrium conversion of roughly around $50 \%$ can be expected. In this instance, an accurate determination of the 


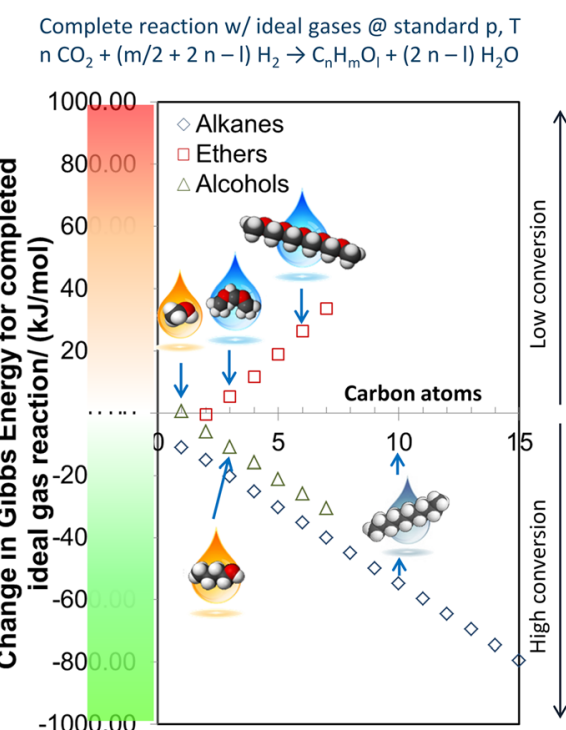

Complete reaction w/ ideal gases @ standard $\mathrm{p}, \mathrm{T}$

$\mathrm{nCO}+(\mathrm{m} / 2+n-\mathrm{I}) \mathrm{H}_{2} \rightarrow \mathrm{C}_{n} \mathrm{H}_{m} \mathrm{O}_{1}+(n-\mathrm{l}) \mathrm{H}_{2} \mathrm{O}$

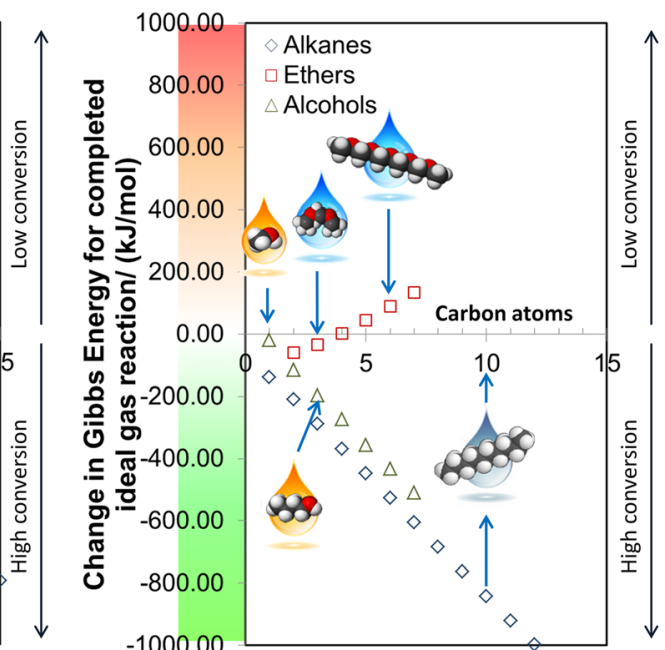

Fig. 7 Gibbs energy analysis for the direct synthesis of various fuels from $\mathrm{H}_{2} / \mathrm{CO}_{2}$ (left) and $\mathrm{H}_{2} / \mathrm{CO}$ (right) mixtures at 1 bar. Red-colored background: low conversion; green-colored background: high conversion (goal)

chemical equilibrium under reaction conditions with a real gas model for high pressures must be performed, as reported by Peters [69]. More details and limitations about the simplified comparison method are also published in [69]. Alkanes can be synthesized by the Fischer-Tropsch process. The chain growth, in turn, can be described by a Schulz-Flory model. Details on the possible mechanism and technical realization are presented by Dry [20]. Figure 7 shows that the change in Gibbs energy increases with increasing chain length. From a practical point of view, Fischer-Tropsch processes end up with wax, which must be cracked to shorter hydrocarbons and subsequently distillated to achieve standard cuts, such a naphtha, kerosene, and diesel. Synthesis paths for higher alcohols were analyzed by Schemme et al. [75]. The simplest alcohol methanol can be produced directly from $\mathrm{CO}_{2}$ and $\mathrm{CO}$. However, as stated by Subramani and Gangwal [83] and He [39], the direct pathway via $\mathrm{CO}_{2}$ hydrogenation is already complex for the $\mathrm{C} 2$-alcohol ethanol. It suffers from a low selectivity and low conversion rate. Other routes include modified methanol and Fischer-Tropsch processes, such as the Ziegler process of mixed alcohol synthesis and aldol or oxo synthesis [75]. Oxo synthesis adds a syngas with carbon monoxide and hydrogen to an olefin and achieves an aldehyde that will be hydrogenated to corresponding alcohols. This route fits perfectly to the intermediates of today's chemistry.

The Ziegler process is based on the oligomerization of ethylene, resulting in a broad range of linear alcohols, as stated by Behr and Falbe $[4,26]$. As in the case of the modified methanol and Fischer-Tropsch process, the Ziegler process leads to insufficient selectivity.

As was mentioned earlier, the direct synthesis of methanol, dimethylether (DME), and methylal $\left(\mathrm{OME}_{1}\right)$ was analyzed by a thermodynamic model using equations of state (Soave Redlich Kwong [82], Peng Robinson [67], and Gibbs energy analysis by Peters [69]). Methylal can only be synthesized if byproducts such as DME and methanol are suppressed by an applicable catalyst. Reaction conditions are quite unfavorable with 100 bar and $413 \mathrm{~K}$ and catalyst activity will not be high at such low temperatures. These results were supported by the relationship between the Gibbs energy change for direct $\mathrm{OME}_{\mathrm{x}}$ synthesis with growing chain length $x$; see Fig. 7 . With increasing carbon chain length, the change in Gibbs energy increases. The values are mostly positive, indicating low conversion for direct $\mathrm{OME}_{\mathrm{x}}$ synthesis.

All direct synthesis reactions can be forcibly rampedup by changing the starting educt molecule from $\mathrm{CO}_{2}$ to $\mathrm{CO}$, which is the commonly used carbon carrier in syngas reactions. The disadvantage of using carbon monoxide for synthesis while starting from carbon dioxide is the implementation of rWGS; see also the chemical equilibrium conditions in Fig. 4. Today, Fischer-Tropsch catalysts only exist for syngas that contains CO. Therefore, rWGS is essential for such a system.

\section{Indirect synthesis of diesel substitutes}

The power-to-fuel concept incorporates technologies such as carbon capture utilization and storage (CCUS), sector coupling in the energy and mobility sectors, and 
fosters the expectation that cleaner fuels eliminate emissions in transportation. Schemme et al. analyzed the power-to-fuel concept as a key to sustainable transport systems, especially for diesel fuels [76]. Potential candidates include $\mathrm{OME}_{3-5}$ and octanol. In this contribution, it should be determined whether these fuels are the optimal ones for renewable fuel production at farm sites. If not, the next research question would be which intermediates are better suited for decentralized production and for subsequent processing at a central site.

Burger described different process routes for the formation of mixtures of polyoxymethylene dimethyl ethers [9]. In this contribution, a process route via the intermediates of trioxane and methylal (route B as proposed by Burger [9]) was chosen. Firstly, methanol is formed at 80 bar and $523 \mathrm{~K}$ :

$$
\begin{aligned}
& \mathrm{CO}_{2}+3 \mathrm{H}_{2} \leftrightarrow \mathrm{CH}_{3} \mathrm{OH}+\mathrm{H}_{2} \mathrm{O} \\
& \Delta_{\mathrm{R}} \mathrm{H}^{\mathrm{o}}=-49.2 \mathrm{~kJ} / \mathrm{mol}
\end{aligned}
$$

An important intermediate is formaldehyde, formed by the partial oxidation of methanol at 1 bar and $903 \mathrm{~K}$ :

$$
\begin{aligned}
& \mathrm{CH}_{3} \mathrm{OH}+\frac{1}{2} \mathrm{O}_{2} \leftrightarrow \mathrm{CH}_{2} \mathrm{O}+\mathrm{H}_{2} \mathrm{O} \\
& \Delta_{\mathrm{R}} \mathrm{H}^{\mathrm{o}}=-156.7 \mathrm{~kJ} / \mathrm{mol}
\end{aligned}
$$

Formaldehyde and two molecules of methanol react to methylal at 2 bar and $33 \mathrm{~K}$ :

$$
\begin{aligned}
& 2 \mathrm{CH}_{3} \mathrm{OH}+\mathrm{CH}_{2} \mathrm{O} \leftrightarrow \mathrm{CH}_{3} \mathrm{OCH}_{2} \mathrm{OCH}_{3}+\mathrm{H}_{2} \mathrm{O} \\
& \Delta_{\mathrm{R}} \mathrm{H}^{\mathrm{o}}=-56.1 \mathrm{~kJ} / \mathrm{mol}
\end{aligned}
$$

In parallel, three molecules of formaldehyde form the intermediate trioxane at 1 bar and $343 \mathrm{~K}$.

$$
3 \mathrm{CH}_{2} \mathrm{O} \leftrightarrow \mathrm{C}_{3} \mathrm{H}_{6} \mathrm{O}_{3} \Delta_{\mathrm{R}} \mathrm{H}^{\mathrm{o}}=-121.2 \mathrm{~kJ} / \mathrm{mol}
$$

Finally, trioxane and methylal form different kinds of $\mathrm{OME}_{\mathrm{x}}$, whereby $x=2$ to 8 . This is displayed as a gross reaction in Eq. (12) at 1 bar and $343 \mathrm{~K}$ :

$$
\begin{aligned}
& \mathrm{C}_{3} \mathrm{H}_{6} \mathrm{O}_{3}+\mathrm{CH}_{3} \mathrm{OCH}_{2} \mathrm{OCH}_{3} \leftrightarrow \mathrm{CH}_{3} \mathrm{O}\left(\mathrm{CH}_{2} \mathrm{O}\right)_{4} \mathrm{CH}_{3} \\
& \Delta_{\mathrm{R}} \mathrm{H}^{\mathrm{o}}=-9.0 \mathrm{~kJ} / \mathrm{mol}
\end{aligned}
$$

This gross reaction can be divided into different reaction steps:

$$
\begin{aligned}
& \mathrm{C}_{3} \mathrm{H}_{6} \mathrm{O}_{3} \leftrightarrow 3 \mathrm{CH}_{2} \mathrm{O} \Delta_{\mathrm{R}} \mathrm{H}^{\mathrm{o}}=56.1 \mathrm{~kJ} / \mathrm{mol} \\
& \mathrm{CH}_{2} \mathrm{O}+\mathrm{CH}_{3} \mathrm{OCH}_{2} \mathrm{OCH}_{3} \leftrightarrow \mathrm{CH}_{3} \mathrm{O}\left(\mathrm{CH}_{2} \mathrm{O}\right)_{2} \mathrm{CH}_{3} \\
& \Delta_{\mathrm{R}} \mathrm{H}^{\mathrm{o}}=-38.3 \mathrm{~kJ} / \mathrm{mol} \\
& \mathrm{CH}_{2} \mathrm{O}+\mathrm{CH}_{3} \mathrm{O}\left(\mathrm{CH}_{2} \mathrm{O}\right)_{2} \mathrm{CH}_{3} \leftrightarrow \mathrm{CH}_{3} \mathrm{O}\left(\mathrm{CH}_{2} \mathrm{O}\right)_{3} \mathrm{CH}_{3} \\
& \Delta_{\mathrm{R}} \mathrm{H}^{\mathrm{o}}=-44.4 \mathrm{~kJ} / \mathrm{mol} \\
& \mathrm{CH}_{2} \mathrm{O}+\mathrm{CH}_{3} \mathrm{O}\left(\mathrm{CH}_{2} \mathrm{O}\right)_{3} \mathrm{CH}_{3} \leftrightarrow \mathrm{CH}_{3} \mathrm{O}\left(\mathrm{CH}_{2} \mathrm{O}\right)_{4} \mathrm{CH}_{3} \\
& \Delta_{\mathrm{R}} \mathrm{H}^{\mathrm{o}}=-44.4 \mathrm{~kJ} / \mathrm{mol}
\end{aligned}
$$

Table 1 shows the change in Gibbs energy and enthalpy for different steps on route B toward OME-4 as published by Burger [9]. In the meantime, the same research group prefers a synthesis via formaldehyde and methanol in aqueous solution termed route A; see Schmitz et al. [77]. The calculations for this paper were performed under idealized conditions for route $B$ in order to get an approximation tool without using Aspen Plus ${ }^{\circ}$ flow sheeting. Gases were approximated as ideal,

\begin{tabular}{|c|c|c|c|c|c|c|c|}
\hline Product & Eq. & p, bar & $\mathrm{T}, \mathrm{K}$ & $\Delta H^{R}(\mathrm{STP}), \mathrm{kJ} / \mathrm{mol}$ & $\Delta \mathrm{G}^{\mathrm{R}}(\mathrm{STP}), \mathrm{kJ} / \mathrm{mol}$ & $\Delta H^{R}(p, T), k J / m o l$ & $\Delta G^{R}(p, T), k J / m o l$ \\
\hline Methanol & (8) & 80 & 523 & -49.2 & 3.5 & -58.7 & 8.3 \\
\hline Formaldehyde & (9) & 1 & 903 & -156.7 & -176.1 & -148.2 & -210.3 \\
\hline Methylal (I) & $(10)$ & 2 & 333 & -72.2 & -20.2 & -60.0 & -30.4 \\
\hline Trioxan (I) & $(11)$ & 1 & 343 & -118.0 & -7.2 & -130.4 & -40.9 \\
\hline OME-4 (I) & $(12)$ & 1 & 343 & -9.0 & 38.1 & -30.7 & 33.2 \\
\hline
\end{tabular}
even at high pressure; liquids were assumed as ideal mixtures. Thermodynamic property data were taken from [68] as a preference dataset. An initial set of information can be gained under standard conditions: all reactions on route $\mathrm{B}$ are exothermic. The change in Gibbs energy is strongly negative only for the partial oxidation of methanol into formaldehyde. Methanol synthesis offers a weakly positive value near to zero, indicating a conversion between 40 and $60 \%$, as already determined more accurately by Peters [69]. Both trioxane and methylal synthesis show a weak negative change in Gibbs energy $\Delta G_{R}$, while $\Delta G_{R}$ is positive for OME-4 synthesis in the liquid phase.

Table 1 Change in Gibbs energy and enthalpy for different steps on route B towards OME-4 published by Burger [9, 76]. Gases were approximated as ideal gas; liquids assumed as ideal mixtures. Thermodynamic property data were taken from Perry and Green for the ideal gas state and liquid state [68] 
Changing pressure and temperature to the reaction conditions improves $\Delta G_{R}$ with respect to the product side for nearly all species except methanol. The catalyst used demands a temperature of between 250 and $300{ }^{\circ} \mathrm{C}$ to be active, which leads to a more positive $\Delta G_{R}$ that must be compensated by a high pressure of about 80 bar. OME- 4 synthesis is even more difficult to realize, at a $\Delta G_{R}$ of $33.6 \mathrm{MJ} / \mathrm{kmol}$.

The assumptions of an ideal mixture in the liquid phase are strongly misleading for the thermodynamic property relations in OME synthesis. The mixtures of different intermediates such as formaldehyde and methylal form various azeotropes and miscibility gaps with water and methanol. Formaldehyde and water form methylene glycols of different chain lengths, whereas formaldehyde and methanol form hemiformals of different chain lengths.

This attempt was successfully developed by Maurer [56] and continued by Albert et al. [1]. These models were then implemented by Schemme [73] with Aspen Plus ${ }^{\circ}$ flow sheeting. Accurate model calculations are highly important for the precise design of separation units between products, byproducts, and intermediates. A quality check of the implemented models was successfully performed by comparing the modeled separation behavior with the experimental data of Burger et al. [10]. The results of the techno-economic evaluation of different process routes for OME synthesis will be published in the near future; see Schemme [73].

Nevertheless, Table 2 shows that the approximation of $\Delta G_{R}$ and $\Delta H_{R}$ by idealized models, i.e., an ideal gas phase and ideal liquid mixture behavior, are confirmed by more complex models, applying an equation of state for polar gases at high pressure and the Universal Quasichemical Functional Group Activity Coefficients (UNIFAC) model for a non-ideal liquid mixture. $\Delta G_{R}$ changes from step to step in the reaction scheme (row to row) to more negative values, as can be seen in Tables 1 and 2. Considering Gibbs energy analysis, the most extensive step in $\mathrm{OME}_{3-5}$ synthesis is methanol formation with medium conversion in the range $40-60 \%$, given a recycling loop or multi-stage synthesis. The final step in the idealized reaction scheme, the formation of $\mathrm{OME}_{4}$ according to Eq. (12), offers a positive $\Delta G_{R}$, indicating lower conversion. Here, a more detailed process analysis is required.

Different pathways for the synthesis of higher alcohols are described by Schemme et al. [75]. Preferred reaction pathways toward 2-butanol and i-octanol are aldol condensation and oxo synthesis.

As was mentioned before, thermodynamic property data for the ideal gas state and pure liquid substances were calculated using formulae listed in [68] if available. Some components, such as crotonaldehyde, are missing from this dataset. Different approximation methods led to noteworthy deviations in certain cases. The enthalpy of formation and Gibbs energy of formation are calculated at $94.3 \mathrm{~kJ} / \mathrm{mol}$ and $-36.5 \mathrm{~kJ} / \mathrm{mol}$, respectively, with the method of Joback and Reid [46]. Da Silva and Bozelli published a measured value for the enthalpy of formation of about $102.1 \pm 0.5 \mathrm{~kJ} / \mathrm{mol}$ [79]. The National Institute of Standards and Technology (NIST) database contains experimental data of between 100.5 and $109.7 \mathrm{~kJ} / \mathrm{mol}$ [14]. With the aid of the computational chemistry comparison and benchmark database of NIST, a standard ideal gas entropy of between 312.4 and $323.7 \mathrm{~kJ} /(\mathrm{mol} \mathrm{K})$ was determined [63]. Assuming a dataset $(\mathrm{H} ; \mathrm{S})$ at standard temperature and pressure in the ideal gas state of about $(-109.7 \mathrm{~kJ} / \mathrm{kmol} ; 314.2 \mathrm{~kJ} /(\mathrm{kmol} \mathrm{K}))$ leads to a Gibbs energy formation of about $-49.2 \mathrm{~kJ} / \mathrm{mol}-$ an increase of $35 \%$, corresponding to the Joback method [46], due to the varying enthalpy of formation.

The following equations explain the reaction scheme of $\mathrm{i}$ octanol by aldol condensation. The reaction pathway begins with methanol synthesis from $\mathrm{CO}_{2}$ and $\mathrm{H}_{2}$ via Eq. (12). Methanol is the educt for a subsequent synthesis of dimethyl ether (DME) at 80 bar and $523 \mathrm{~K}$ :

$$
2 \mathrm{CH}_{3} \mathrm{OH} \leftrightarrow \mathrm{CH}_{3} \mathrm{O} \mathrm{CH} \mathrm{H}_{3}+\mathrm{H}_{2} \mathrm{O} \Delta_{\mathrm{R}} \mathrm{H}^{\mathrm{o}}=-24.0 \mathrm{~kJ} / \mathrm{mol}
$$

Other pathways, such as a direct synthesis of DME from $\mathrm{CO}_{2}$ and $\mathrm{H}_{2}$ or parallel chemical reactions (Eqs.

Table 2 Change in Gibbs energy and enthalpy for different steps on route B towards OME-4, published by Burger [9, 76]. Columns 5 and 6 show gases that were approximated as ideal even at high pressure; liquids were assumed as ideal mixtures (IG: ideal Gas, IM, ideal mixture). Columns 7 and 8 indicate gases that were approximated as real gases (RG) with an equation of state, i.e., polar Soave Redling Kwong, even at high pressure and liquids assumed as real mixtures with UNIFAC as $G^{E}$ model for excess Gibbs energy of mixture

\begin{tabular}{llllllll}
\hline Product & Eq. & $\mathrm{p}$, bar & $\mathrm{T}, \mathrm{K}$ & $\Delta \mathrm{H}^{\mathrm{R}}(\mathrm{IG}, \mathrm{IM}), \mathrm{kJ} / \mathrm{mol}$ & $\Delta \mathrm{G}^{\mathrm{R}}(\mathrm{IG}, \mathrm{IM}), \mathrm{kJ} / \mathrm{mol}$ & $\Delta \mathrm{H}^{\mathrm{R}}\left(\mathrm{RG}, \mathrm{G}^{\mathrm{E}}\right), \mathrm{kJ} / \mathrm{mol}^{\mathrm{N}}$ & $\Delta \mathrm{G}^{\mathrm{R}}\left(\mathrm{RG}, \mathrm{G}^{\mathrm{E}}\right), \mathrm{kJ} / \mathrm{mol}^{\prime}$ \\
\hline Methanol & $(8)$ & 80 & 523 & -58.7 & 8.3 & -72.0 & 5.1 \\
Formaldehyde & $(9)$ & 1 & 903 & -148.2 & -210.3 & -56.5 & -217.8 \\
Methylal (I) & $(10)$ & 2 & 333 & -60.0 & -30.4 & -126.4 & -30.0 \\
Trioxan (I) & $(11)$ & 1 & 343 & -130.4 & -40.9 & -38.9 \\
OME-4 (I) & $(12)$ & 1 & 343 & -30.7 & 33.2 & -29.5 & -33.6 \\
\hline
\end{tabular}


(12), (13)) on a bi-functional catalyst, were reported by Krause and Keskinen [50]. For the next step, syngas is required that can be produced by reverse water-gas shift reaction, see Eq. (3). Carbon monoxide and DME form methyl acetate at $140 \mathrm{bar}$ and $478 \mathrm{~K}$.

$$
\begin{aligned}
& \mathrm{CO}+\mathrm{CH}_{3} \mathrm{O} \mathrm{CH}_{3} \leftrightarrow \mathrm{CH}_{3} \mathrm{COO} \mathrm{CH}_{3} \\
& \Delta_{\mathrm{R}} \mathrm{H}^{\mathrm{o}}=-117.3 \mathrm{~kJ} / \mathrm{mol}
\end{aligned}
$$

Ethyl acetate itself decomposes into methanol and ethanol at 140 bar and $478 \mathrm{~K}$ :

$$
\begin{aligned}
& \mathrm{CH}_{3} \mathrm{COO} \mathrm{CH}_{3} \leftrightarrow \mathrm{CH}_{3} \mathrm{OH}+\mathrm{C}_{2} \mathrm{H}_{5} \mathrm{OH} \\
& \Delta_{\mathrm{R}} \mathrm{H}^{\mathrm{o}}=-24.0 \mathrm{~kJ} / \mathrm{mol}
\end{aligned}
$$

The direct synthesis of ethanol from $\mathrm{CO}_{2}$ and $\mathrm{H}_{2}$ is less maturate, as Schemme et al. [75] reported. The change in Gibbs energy for direct ethanol synthesis amounts to $59.3 \mathrm{~kJ} / \mathrm{mol}$. Ethanol synthesis via DME offers a value of $31.2 \mathrm{~kJ} / \mathrm{mol}$ under real gas conditions, which indicates that this route can also be realized with sufficient conversion.

Afterwards, ethanol is dehydrogenated at $1 \mathrm{bar}$ and $673 \mathrm{~K}$ :

$$
\mathrm{C}_{2} \mathrm{H}_{5} \mathrm{OH} \leftrightarrow \mathrm{C}_{2} \mathrm{H}_{4} \mathrm{O}+\mathrm{H}_{2} \Delta_{\mathrm{R}} \mathrm{H}^{\mathrm{o}}=68.8 \mathrm{~kJ} / \mathrm{mol}
$$

Two ethanol molecules go into the aldol condensation, forming croton aldehyde and water at 70 bar and $493 \mathrm{~K}$.

$$
2 \mathrm{C}_{2} \mathrm{H}_{4} \mathrm{O} \leftrightarrow \mathrm{C}_{4} \mathrm{H}_{6} \mathrm{O}+\mathrm{H}_{2} \mathrm{O} \Delta_{\mathrm{R}} \mathrm{H}^{\mathrm{o}}=-18.9 \mathrm{~kJ} / \mathrm{mol}
$$

Croton aldehyde is hydrogenated to 1-butanol at 70 bar and $493 \mathrm{~K}$.

$$
\mathrm{C}_{4} \mathrm{H}_{6} \mathrm{O}+2 \mathrm{H}_{2} \leftrightarrow \mathrm{C}_{4} \mathrm{H}_{9} \mathrm{OH} \Delta_{\mathrm{R}} \mathrm{H}^{0}=-165.1 \mathrm{~kJ} / \mathrm{mol}
$$

Butanol is dehydrogenated to butanal at 70 bar and $493 \mathrm{~K}$.

$$
\mathrm{C}_{4} \mathrm{H}_{9} \mathrm{OH} \leftrightarrow \mathrm{C}_{4} \mathrm{H}_{8} \mathrm{O}+2 \mathrm{H}_{2} \Delta_{\mathrm{R}} \mathrm{H}^{0}=67.6 \mathrm{~kJ} / \mathrm{mol}
$$

Two butanal molecules go into the aldol condensation, forming 2-ethylhexen-1-al (IUPAC name [62] and water at $1 \mathrm{bar}$ and $323 \mathrm{~K}$.

$$
\begin{aligned}
& 2 \mathrm{C}_{4} \mathrm{H}_{8} \mathrm{O} \leftrightarrow \mathrm{C}_{5} \mathrm{H}_{8}\left(\mathrm{C}_{2} \mathrm{H}_{5}\right) \mathrm{CHO}+\mathrm{H}_{2} \mathrm{O} \\
& \Delta_{\mathrm{R}} \mathrm{H}^{0}=-24 \mathrm{~kJ} / \mathrm{mol}
\end{aligned}
$$

2-Ethylhexen-1-al will be hydrogenated to 2ethylhexan-1-ol at 1 bar and $323 \mathrm{~K}$.

$$
\begin{aligned}
& \mathrm{C}_{5} \mathrm{H}_{8}\left(\mathrm{C}_{2} \mathrm{H}_{5}\right) \mathrm{CHO}+2 \mathrm{H}_{2} \leftrightarrow \mathrm{C}_{5} \mathrm{H}_{10}\left(\mathrm{C}_{2} \mathrm{H}_{5}\right) \mathrm{CH}_{2} \mathrm{OH} \\
& \Delta_{\mathrm{R}} \mathrm{H}^{0}=-168.8 \mathrm{~kJ} / \mathrm{mol}
\end{aligned}
$$

The molecule 2-ethylhexan-1-ol is one type of various isomers of isooctanol and will, for sake of simplicity, be labeled as ethylhexanol in the following sections.

Table 3 shows the change in Gibbs energy and enthalpy for different steps toward 1-butanol and i-octanol as published by Schemme [75]. Gases were approximated as ideal, liquids assumed as ideal mixtures. Thermodynamic property data were taken from Perry and Green for the ideal gas state and liquid state, except for crotonaldehyde, 2-ethyl hexenal, and 2-ethyl hexanol. (H, S, G)-data for crotonaldehyde were based on values given by NIST [63, 64], (H, S, G)-data for 2-

\begin{tabular}{|c|c|c|c|c|c|c|c|}
\hline Product & Eq. & p, bar & $\mathrm{T}, \mathrm{K}$ & $\Delta H^{R}(S T P), k J / m o l$ & $\Delta \mathrm{G}^{\mathrm{R}}(\mathrm{STP}), \mathrm{kJ} / \mathrm{mol}$ & $\Delta H^{R}(p, T), k J / m o l$ & $\Delta \mathrm{G}^{\mathrm{R}}(\mathrm{p}, \mathrm{T}), \mathrm{kJ} / \mathrm{mol}$ \\
\hline Methanol & (8) & 80 & 523 & -49.2 & 5.6 & -39.1 & 12.1 \\
\hline Dimethylether & $(17)$ & 50 & 523 & -24.0 & -20.2 & -21.7 & -18.0 \\
\hline Carbon monoxide & (3) & 1 & 1073 & 41.2 & 28.6 & 34.1 & 0.8 \\
\hline Methyl actetate & (18) & 140 & 478 & -117.3 & -70.8 & -118.3 & -62.0 \\
\hline Ethanol & (19) & 140 & 478 & -24.0 & -4.7 & -18.9 & -107.0 \\
\hline Ethanal & $(20)$ & 1 & 673 & 68.8 & 31.3 & 72.9 & -18.1 \\
\hline Croton aldehyde (I) & $(21)$ & 70 & 493 & -1.8 & 4.8 & -56.7 & -4.8 \\
\hline Butanol (I) & $(22)$ & 70 & 493 & -173.2 & -108.5 & -183.4 & -142.1 \\
\hline Butanal (g) & $(23)$ & 1 & 673 & 68.9 & 35.9 & 85.2 & -13.7 \\
\hline 2-ethyl-hexen-1-al & $(24)$ & 1 & 323 & -19.7 & -16.5 & -46.4 & -30.1 \\
\hline 2-ethyl-hexan-1-ol & $(25)$ & 1 & 323 & -167.0 & -99.4 & -188.6 & -151.01 \\
\hline
\end{tabular}
ethyl hexenal, and 2-ethyl hexanol were determined using the method of Joback and Reid [46]. Calculated data for 1octanol and 2-ethyl hexanol offers minor deviations compared to Joback, NIST, and the Korea Thermophysical Properties Data Bank (KDB) data base [14, 46, 64].

Table 3 indicates that most processes in the considered octanol synthesis process chain are exothermic, except for the dehydrogenation of ethanol and butanol to ethanal and butanal and for the reverse water gas shift reaction. As can be seen from Eqs. (20) and (23), as well

Table 3 Change in Gibbs energy and enthalpy for different steps toward 1-butanol and i-octanol as published by Schemme [75] 
as Table 3, dehydrogenation at standard pressure and temperature is characterized by a positive change in enthalpy and in Gibbs energy. Endothermic reactions should be performed at elevated temperatures. An increase in moles during a chemical reaction is better realized at low pressure. Following the principle of Le Chatelier, the chemical reaction of dehydrogenation is considered at 1 bar and $673 \mathrm{~K}$. Under these assumptions, the changes in Gibbs energy towards the products ethanal and butanal amount to $-18.1 \mathrm{~kJ} / \mathrm{mol}$ and $-13.7 \mathrm{~kJ} /$ mol, respectively, for the ideal gas state.

The reverse water gas shift reaction is indicated by a positive $\Delta G_{\mathrm{R}}$ of about $28.6 \mathrm{~kJ} / \mathrm{mol}$, which leads to a conversion of much less than $5 \%$ under standard conditions; see Fig. 4.

At $1073 \mathrm{~K}$ change in Gibbs energy, $\Delta \mathrm{G}_{\mathrm{R}}$ amounts to $0.8 \mathrm{~kJ} / \mathrm{kmol}$, leading to a conversion higher than $80 \%$. According to Eq. (19), high pressure enhances the formation of ethanol and methanol from ethylacetate, which is indicated by an improvement for $\Delta G_{R}$ from $4.7 \mathrm{~kJ} / \mathrm{mol}$ at standard conditions to $-107 \mathrm{~kJ} / \mathrm{mol}$ at 140 bar and $478 \mathrm{~K}$. The most difficult step seems to be the formation of croton aldehyde via reaction (21). The formation of ethylhexenal and ethylhexanol are both improved at slightly elevated temperatures of $323 \mathrm{~K} . \Delta \mathrm{G}_{\mathrm{R}}$ amounts to $-30.1 \mathrm{~kJ} / \mathrm{kmol}$ under 70 bar and $493 \mathrm{~K}$.

A heat integration concept can be derived if all duties and heat sources are defined. A more detailed analysis of the complete process chain will be discussed in the next section. The number of required process units will also be graphically indicated.

\section{Process analysis}

The aim of this section is to consider the question of which fuels or intermediates are suitable for production from biogas and can be temporarily stored on a farm. With regard to the production of a diesel substitute, the selected pathways toward higher alcohols or ethers should be analyzed. The principle steps in the $\mathrm{OME}_{3-5}$ synthesis on route $\mathrm{B}$, originally proposed by Burger [9], are implemented in Eqs. (8)-(16) and summarized in Table 1 and Table 2. The research group of the Technical University of Munich [10, 11, 40,77] recently preferred route A, whereby the synthesis of intermediates trioxane and methylal can be avoided. The disadvantage of this route is a wet $\mathrm{OME}_{3-5}$ synthesis process, in combination with a complex separation system. For the synthesis of higher alcohols on the route of aldol condensation reported recently by Schemme et al. [75], chemical reactions, Gibbs energy, and the heat of the reaction data are given in Eqs. (17)-(25) and summarized in Table 3.

In order to elucidate the effort for different fuel synthesis systems, a new scheme was developed. Process units such as heat exchangers, mixers, distillation columns, pumps, compressors, and chemical reactors were sketched on a checkered field in individual positions. On the $y$-axis, each center line between two rows represents another pure substance or a mixture of educts or products. Pure substances are, for example, water/steam and trioxane, while a mixture is in the liquid state methanol-water or a gaseous mixture $\mathrm{H}_{2}$ and $\mathrm{CO}_{2}$. On the $x$-axis, each new process unit demanded induces a step to the right. Symbols were always positioned on the intercept points of the grid.

Figure 8 starts in the lower left-hand corner with the compression and mixing of carbon dioxide and hydrogen on lines 1-3. After pre-heating the gaseous educt mixture, a methanol-water mixture was produced over a catalyst in a chemical synthesis reactor. Methanol and water are separated via distillation and fed into two provision/removal pipelines. The required recycling loop with the separation of the non-converted gases from the liquid product phase is only implied by a recycling sign. In the case that a distillation demands two columns, only one step is performed to the right; four columns, i.e., two pairs at different pressures to overcome azeotropes, are indicated by moving two lines to the right.

$\mathrm{OME}_{3-5}$ via intermediates methylal and trioxane occupy 17 horizontal and 22 vertical lines in such a sketch. Figure 9 shows the principle flow sheet of the multi-stage synthesis of 2-ethylhexanol via aldol condensation from butanol reported by Schemme et al. [75]. This synthesis route requires 22 horizontal and 19 vertical lines. In turn, ethylhexanol synthesis demands more chemical reaction steps compared to $\mathrm{OME}_{3-5}$ synthesis, resulting in the higher number of horizontal lines. However, the process of $\mathrm{OME}_{3-5}$ synthesis demands more thermal separation units related to alcohol synthesis, resulting in the higher number of vertical lines. The complexity of these separation steps is caused by the non-ideal thermodynamic properties of the different reaction steps in ether synthesis. Details on thermodynamic modeling can be found in Schemme [73].

Considering an optional cut between the decentralized synthesis of an intermediate at the farm site and centralized fuel synthesis, methanol is definitely the preferred species in the case of $\mathrm{OME}_{3-5}$ synthesis. This is caused by the junction of parallel synthesis pathways for trioxane and methylal, forming the desired product of $\mathrm{OME}_{\mathrm{x}}$ in a final step. Therefore, $\mathrm{OME}_{3-5}$ was not considered for process optimization at the farm site. In the case of alcohol synthesis, methanol, ethanol, and butanol are applicable intermediates. DME can only be chosen with a modification of the synthesis pathway. Nevertheless, both process chains toward $\mathrm{OME}_{3-5}$ and 2-ethylhexanol require a large amount of intermediate chemical reaction steps and, for some cases, a fairly complex and extensive separation processes. In the next section, 


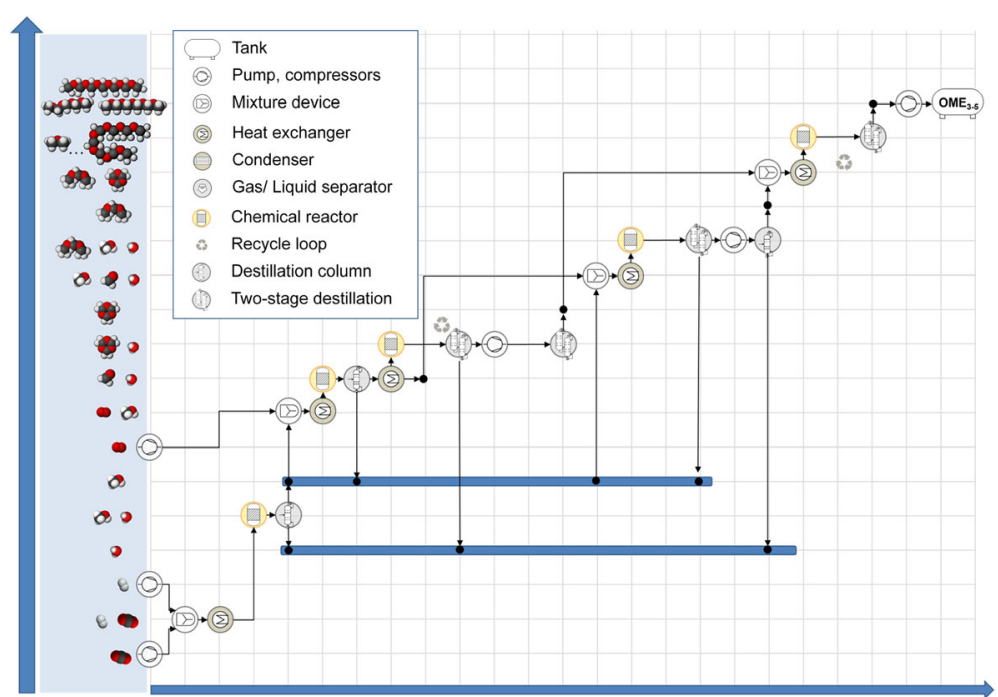

Fig. 8 Principle flow sheet of multi-stage synthesis of $\mathrm{OME}_{3-5}$ via methylal and trioxane, route $\mathrm{B}$; see also Burger [9]. For example: line 2 with molecules $\mathrm{H}_{2}, \mathrm{CO}_{2}$ as educts in Eq. (8); line 5 with molecules $\mathrm{CH}_{3} \mathrm{OH}, \mathrm{H}_{2} \mathrm{O}$ as products in in Eq. (8). Next example: line 8 with molecules $\mathrm{CH}_{3} \mathrm{OH}$, $\mathrm{O}_{2}$ as educts in Eq. (9); line 9 with molecules $\mathrm{CH}_{2} \mathrm{O}, \mathrm{H}_{2} \mathrm{O}$ as products in in Eq. (9)

optimization toward process simplification will be discussed.

\section{Process design for optimized synthesis processes}

In this section, a series of purely stoichiometric conceivable chemical reactions, starting from biogas, are presented and an estimate of their corresponding chemical and thermodynamic feasibility is given. Generally, this exercise should enable a broader perspective on the possible pathways to be gained. The biogas components of methane and carbon dioxide may react directly to acetic acid, as conveyed in Eq. (26):

$$
\mathrm{CH}_{4}+\mathrm{CO}_{2} \leftrightarrow \mathrm{H}_{3} \mathrm{C}-\mathrm{COOH} \Delta_{\mathrm{R}} \mathrm{H}^{\mathrm{o}}=35.2 \mathrm{~kJ} / \mathrm{mol}
$$

The formed acetic acid could be hydrogenated in a subsequent reaction to form ethanol.

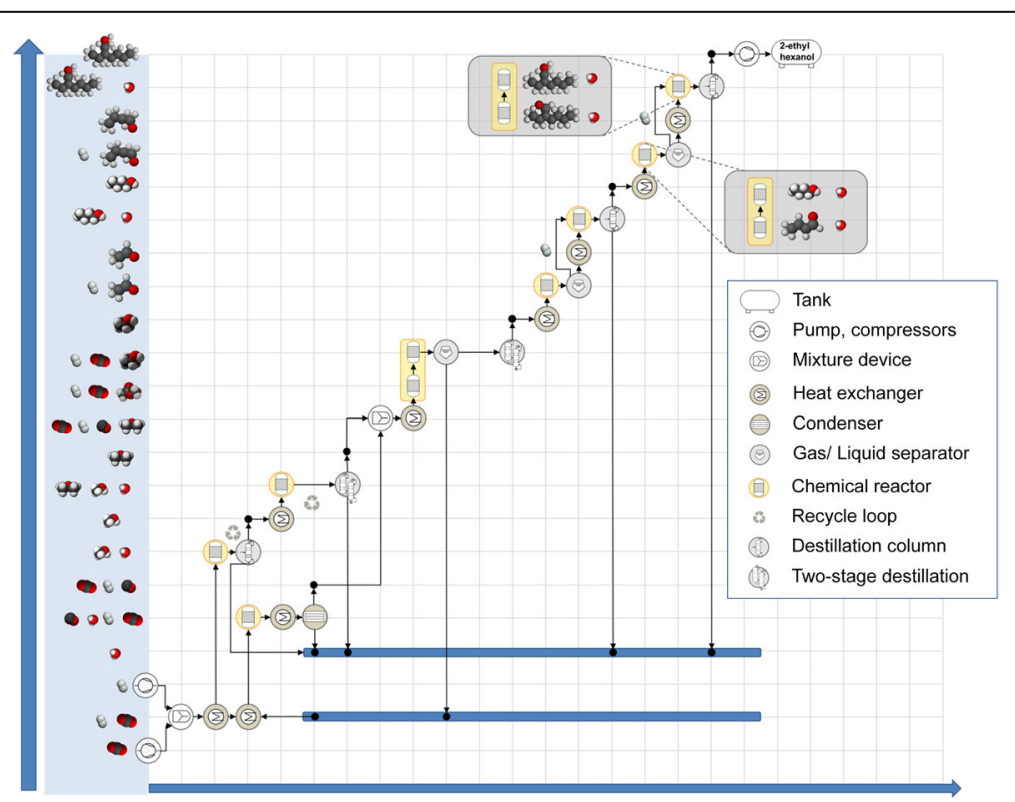

Fig. 9 Principle flow sheet of multi-stage synthesis of 2-ethylhexanol via aldol condensation from butanol as reported by Schemme et al. [75]. For example: line 14 with molecule $\mathrm{C}_{2} \mathrm{H}_{5} \mathrm{OH}$ as educt in Eq. (20); line 15 with molecules $\mathrm{H}_{2}, \mathrm{C}_{2} \mathrm{H}_{4} \mathrm{O}$, as products in in Eq. (20) 


$$
\begin{aligned}
& \mathrm{H}_{3} \mathrm{C}-\mathrm{COOH}+2 \mathrm{H}_{2} \leftrightarrow \mathrm{H}_{5} \mathrm{C}_{2} \mathrm{OH}+\mathrm{H}_{2} \mathrm{O} \\
& \Delta_{\mathrm{R}} \mathrm{H}^{\mathrm{o}}=-44.0 \mathrm{~kJ} / \mathrm{mol}
\end{aligned}
$$

Figure 10 shows the principle flow sheet for acetic acid synthesis from methane and carbon dioxide in combination with an energy analysis in G,H-diagram under standard ideal gas state conditions (STP).

Thermodynamic calculations indicate a difference in Gibbs energy for a completed reaction to acetic acid of about $73.7 \mathrm{~kJ} / \mathrm{mol}$ ethanol. Methane is a stable molecule, due to its tetrahedral structure. As was already shown in Fig. 5, for the dry reforming of methane, high temperatures (and a catalyst) are required to activate the $\mathrm{C}-\mathrm{H}$ bond in methane for a further chemical reaction.

As a second "option," carbon monoxide can be formed via reverse water gas shift reaction, as in Eq. (3). Subsequently, methane and carbon monoxide form ethanal (see Eq. (28)), which can be hydrogenated into ethanol.

$$
\mathrm{CH}_{4}+\mathrm{CO} \leftrightarrow \mathrm{H}_{3} \mathrm{C}-\mathrm{HC}=\mathrm{O} \Delta_{\mathrm{R}} \mathrm{H}^{\mathrm{o}}=18.85 \mathrm{~kJ} / \mathrm{mol}
$$

The difference in Gibbs energy for a completed reaction to ethanal amounts to $58 \mathrm{~kJ} / \mathrm{mol}$ ethanol, as can be seen in Fig. 11. Due to the implementation of a reverse water gas shift reactor, the process scheme includes more elements related to Fig. 10.

The formation of methyl acetate from dimethyl ether and carbon monoxide is an important reaction step toward ethanol according to Eq. (18). Equation (29) offers a chemical reaction between methanol and carbon monoxide, forming acetic acid. The process was originally developed by BASF in 1960. A corresponding plant was built by Monsanto in Texas that applied an improved catalyst, as reported by Roth [72].

$$
\begin{aligned}
& \mathrm{CH}_{3} \mathrm{OH}+\mathrm{CO} \leftrightarrow \mathrm{H}_{3} \mathrm{C}-\mathrm{COOH} \\
& \Delta_{\mathrm{R}} \mathrm{H}^{\mathrm{o}}=-121.3 \mathrm{~kJ} / \mathrm{mol}
\end{aligned}
$$

Figure 12 shows the principle flow sheet for acetic acid synthesis from methanol and carbon monoxide, in combination with an energy analysis in G,H-diagram under standard ideal gas state conditions (STP). In comparison to Fig. 9, the number of pure components and mixtures on the $y$-axis decreases from 14 to 12 , while the number of elements decreases from 20 to 17, indicating a slight improvement. A noteworthy disadvantage is the formation of a water-ethanol solution. Its separation requires a second distillation column due the azeotrope in the system. The proposed pathway via DME (see Fig. 9) results in the distillation of ethanol and methanol, which forms no azeotropes.

Figure 12 shows that both reaction steps achieve negative changes in Gibbs energy at standard conditions in the ideal gas state. From a thermodynamic point of view, this approach is very rough because the Monsanto process is performed as a homogeneously catalyzed reaction in the liquid phase at 30-60 bar and $423-473 \mathrm{~K}$ applying a Rh-complex catalyst; see [72].

The methanol-to-olefin process offers a further option for producing alcohols. For an olefin $\mathrm{C}_{n} \mathrm{H}_{2 n}$ from methanol, the following synthesis reaction occurs, resulting in various olefins:

$$
\text { n } \mathrm{CH}_{3} \mathrm{OH} \leftrightarrow \mathrm{C}_{n} \mathrm{H}_{2 n}+\mathrm{n} \mathrm{H}_{2} \mathrm{O} \Delta_{\mathrm{R}} \mathrm{H}^{\mathrm{o}}>0 \mathrm{~kJ} / \mathrm{mol}
$$

Kvisle et al. reported on different MTG/methanol to olefins (MTO) technologies. Using different catalysts, product spectra such as $5 \% \mathrm{C}_{1}-\mathrm{C}_{3}$ paraffins, $50 \%$ ethene, $35 \%$ propene, and $10 \%$ butane and higher hydrocarbons, or $5 \% \mathrm{C}_{1}-\mathrm{C}_{3}$ paraffins, $8 \%$ ethane, $45 \%$ propene, and $45 \%$ butane and higher hydrocarbons are achievable [52]. A commercial plant from universal oil products (UOP) gains a yield of $\sim 50 \%$ mass from $3000 \mathrm{t} / \mathrm{a}$ with a

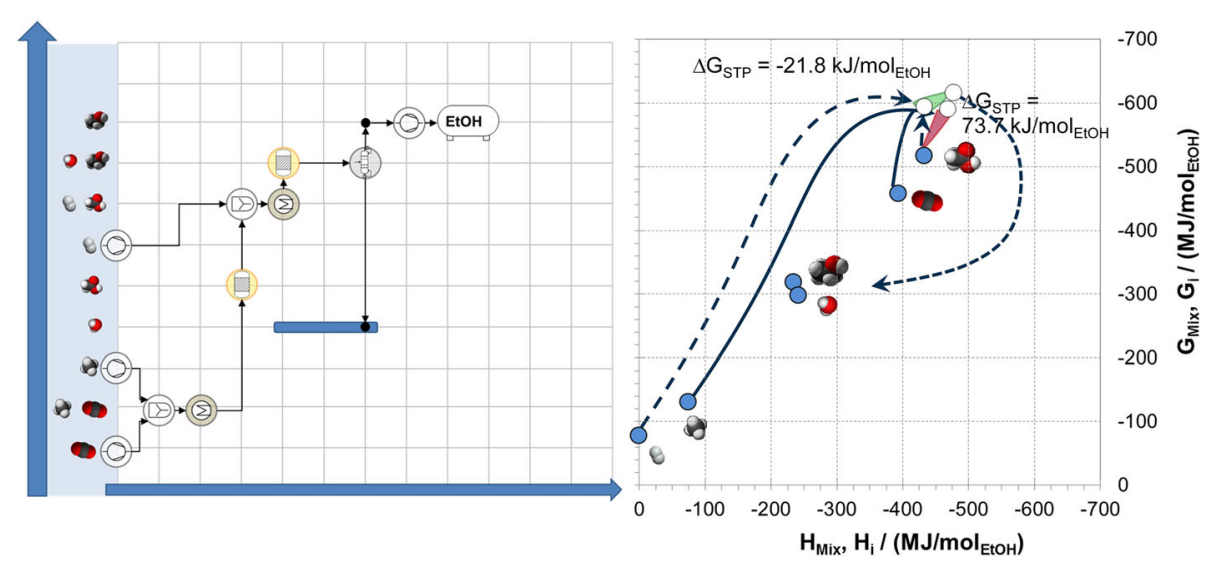

Fig. 10 Principle flow sheet for acetic acid synthesis from methane and carbon dioxide in combination with an energy analysis in G,H-diagram under standard ideal gas state conditions (STP). Symbols see legend in Figs. 8 and 9 


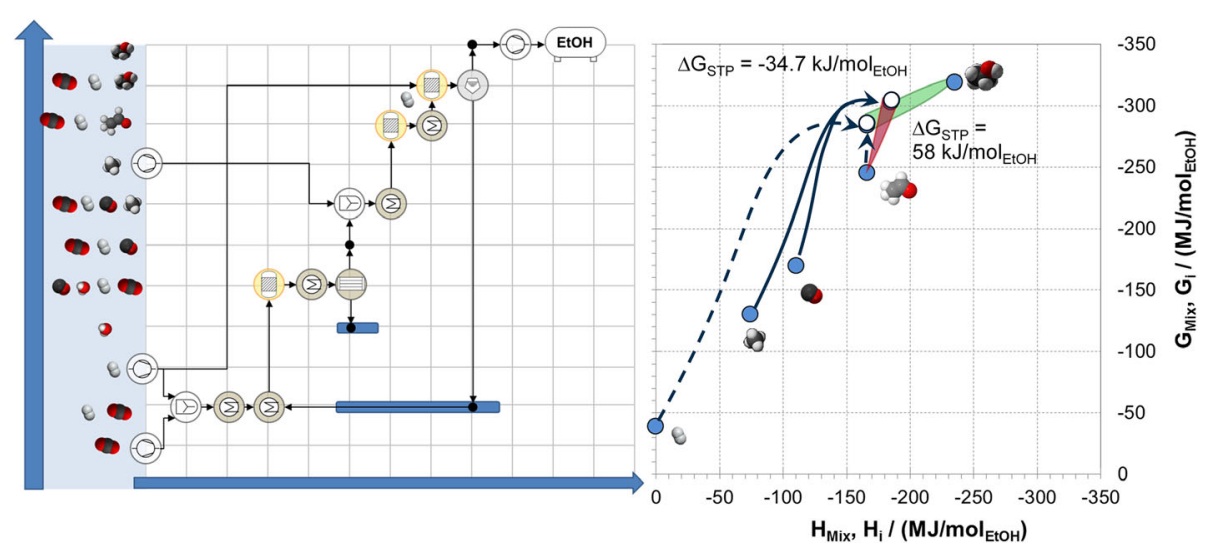

Fig. 11 Principle flow sheet for ethanol synthesis from methane and carbon monoxide, in combination with an energy analysis in G,H-diagram under standard ideal gas state conditions (STP). Symbols see legend in Figs. 8 and 9

yearly production of $500 \mathrm{t}$ ethene (17\%), $500 \mathrm{t}$ propene (17\%), and $167 \mathrm{t}$ butane (5.6\%).

Oelfins can also be formed from DME by the following:

$$
\begin{aligned}
& \mathrm{n} / 2 \mathrm{CH}_{3} \mathrm{OCH}_{3} \leftrightarrow \mathrm{C}_{n} \mathrm{H}_{2 n}+\mathrm{n} / 2 \mathrm{H}_{2} \mathrm{O} \\
& \Delta_{\mathrm{R}} \mathrm{H}^{\mathrm{o}}>0 \mathrm{~kJ} / \mathrm{mol}
\end{aligned}
$$

Table 4 shows the change in Gibbs energy and enthalpy for different steps from methanol and DME to olefins. The values for the change in Gibbs energy during the reaction and heat of the reaction differ only slightly between the different models.

In a subsequent step, alcohols can be produced from the olefins ethene, propene, and butane; see [23]. Butanol can also be formed from butene via hydration:

$$
\begin{aligned}
& \mathrm{H}_{3} \mathrm{C}-\mathrm{CH}_{2}-\mathrm{CH}=\mathrm{CH}_{2}+\mathrm{H}_{2} \mathrm{O} \leftrightarrow \mathrm{H}_{9} \mathrm{C}_{4} \mathrm{OH} \\
& \Delta_{\mathrm{R}} \mathrm{H}^{\mathrm{o}}=-32.2 \mathrm{~kJ} / \mathrm{mol}
\end{aligned}
$$

As stated by Latscha et al., water can only be added in the presence of an acid, as water itself is not electrophilic enough [53]. It is important to ensure that an acid is used whose anion is as nucleophobic as possible so that it does not compete with water; otherwise, product mixtures are formed. Sulfuric acid is often used for this purpose. Nevertheless, in the case of longer-chain alkenes, product mixtures may result, as typical carbenium ion side reactions can occur at the carbenium ion stage.

For the product propene, the oxo synthesis with syngas can be performed as follows:

$$
\begin{aligned}
& \mathrm{H}_{3} \mathrm{C}-\mathrm{CH}=\mathrm{CH}_{2}+\mathrm{CO} \leftrightarrow \mathrm{H}_{3} \mathrm{C}-\mathrm{CH}=\mathrm{CH}-\mathrm{HC}=\mathrm{O} \\
& \Delta_{\mathrm{R}} \mathrm{H}^{\mathrm{o}}=-18.9 \mathrm{~kJ} / \mathrm{mol}
\end{aligned}
$$

The formed croton aldehyde is subsequently hydrogenated to butanol according to:

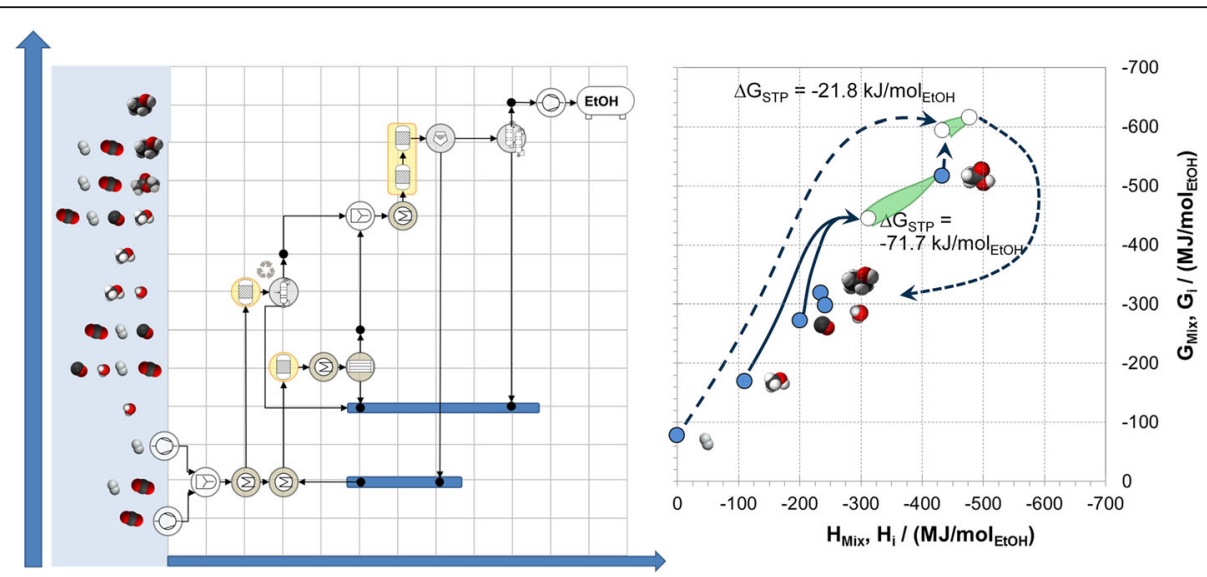

Fig. 12 Principle flow sheet for acetic acid synthesis from methanol and carbon monoxide, in combination with an energy analysis in G,H-diagram under standard ideal gas state conditions (STP). Symbols see legend in Figs. 8 and 9 
Table 4 Change in Gibbs energy and enthalpy for different steps from methanol and DME to olefins. The gases in rows 4-7 were approximated as ideal; the liquids assumed as ideal mixtures. Thermodynamic property data were taken from [68] for ideal gas and liquid states. The real gases in rows 8 and 9 were calculated by Aspen Plus ${ }^{\circledR}$ with a modified EOS SRK for polar components [81]

\begin{tabular}{|c|c|c|c|c|c|c|}
\hline Quantity & $\mathrm{C}_{2} \mathrm{H}_{4}$ from $\mathrm{CH}_{3} \mathrm{OH}$ & $\mathrm{C}_{3} \mathrm{H}_{6}$ from $\mathrm{CH}_{3} \mathrm{OH}$ & $\mathrm{C}_{4} \mathrm{H}_{8}$ from $\mathrm{CH}_{3} \mathrm{OH}$ & $\mathrm{C}_{2} \mathrm{H}_{4}$ from DME & $\mathrm{C}_{3} \mathrm{H}_{6}$ from DME & $\mathrm{C}_{4} \mathrm{H}_{8}$ from $\mathrm{DME}$ \\
\hline p. bar & 3.5 & 3.5 & 3.5 & 3.5 & 3.5 & 3.5 \\
\hline T. K & 788 & 788 & 788 & 788 & 788 & 788 \\
\hline$\Delta H^{\text {R.id }}$ (STP). $\mathrm{kJ} / \mathrm{mol}$ & -29.2 & -102.9 & -164.0 & -5.2 & -66.9 & -116.0 \\
\hline$\Delta \mathrm{G}^{\text {R.id }}$ (STP). $\mathrm{kJ} / \mathrm{mol}$ & -64.1 & -136.6 & -194.8 & -47.3 & -111.5 & -161.2 \\
\hline$\Delta H^{\text {R.id }}($ p.T). $\mathrm{kJ} / \mathrm{mol}$ & -23.4 & -93.6 & -159.4 & -3.5 & -63.8 & -110.6 \\
\hline$\Delta G^{\text {R.id }}($ p.T). $\mathrm{kJ} / \mathrm{mol}$ & -130.3 & -205.7 & -263.5 & -119.2 & -190.5 & -244.3 \\
\hline$\Delta H^{R . R G}(p . T) . k J / m o l$ & -23.4 & -93.1 & -150.3 & -3.5 & -63.4 & -110.6 \\
\hline$\Delta \mathrm{G}^{\mathrm{R} . R G}$ (p.T). $\mathrm{kJ} / \mathrm{mol}$ & -117.7 & -190.5 & -246.7 & -110.3 & -179.3 & -231.8 \\
\hline
\end{tabular}

$$
\begin{aligned}
& \mathrm{H}_{3} \mathrm{C}-\mathrm{CH}=\mathrm{CH}-\mathrm{HC}=\mathrm{O}+2 \mathrm{H}_{2} \leftrightarrow \mathrm{H}_{9} \mathrm{C}_{4} \mathrm{OH} \\
& \Delta_{\mathrm{R}} \mathrm{H}^{\mathrm{o}}=-165.1 \mathrm{~kJ} / \mathrm{mol}
\end{aligned}
$$

The last main product of the MTO process ethene can react with water to ethanol by hydration.

$$
\begin{aligned}
& \mathrm{H}_{2} \mathrm{C}=\mathrm{CH}_{2}+\mathrm{H}_{2} \mathrm{O} \leftrightarrow \mathrm{H}_{5} \mathrm{C}_{2} \mathrm{OH} \\
& \Delta_{\mathrm{R}} \mathrm{H}^{\mathrm{o}}=-32.2 \mathrm{~kJ} / \mathrm{mol}
\end{aligned}
$$

Fougret and Hölderich applied metal phosphates (containing aluminum, zircon and cerium) at $300{ }^{\circ} \mathrm{C}$ and 50 bar, which were then impregnated with phosphoric acid [27]. Selectivity reaches $99.9 \%$ with small amounts of acetaldehyde as a by-product. Via aldol condensation butanol can be gained; see Eqs. (20)-(22). Figure 13 shows a principle flow sheet for butanol synthesis from methanol via the oxo synthesis of propene and carbon monoxide, in combination with an energy analysis in a G,H-diagram under standard ideal gas state conditions
(STP). In comparison to Fig. 9, the number of pure components and mixtures on the $y$-axis remains 14 , while the number of elements decreases slightly, from 20 to 19. Both cases of oxo synthesis form either DME or, from methanol, reach the same complexity. An advantage of the process is the good separation of butane and water indicated by the large difference in Gibbs energy for water and butane. According to the change in Gibbs energy, it seems that $\mathrm{CO}$ feeding is more difficult to realize than the hydrogenation of crotonaldehyde. Figure 14 shows a principle flow sheet for butanol synthesis from methanol via butene hydration, in combination with an energy analysis in the G,H-diagram under standard ideal gas state conditions (STP). In comparison to Fig. 9, the number of pure components and mixtures on the $y$-axis decrease from 14 to 9 , while the number of elements decreases drastically, from 20 to 12 . The change in Gibbs energy for butane hydration amounts to $8 \mathrm{~kJ} /$ mol butanol, indicating an equilibrium conversion of about $50 \%$ under standard conditions. If the reaction

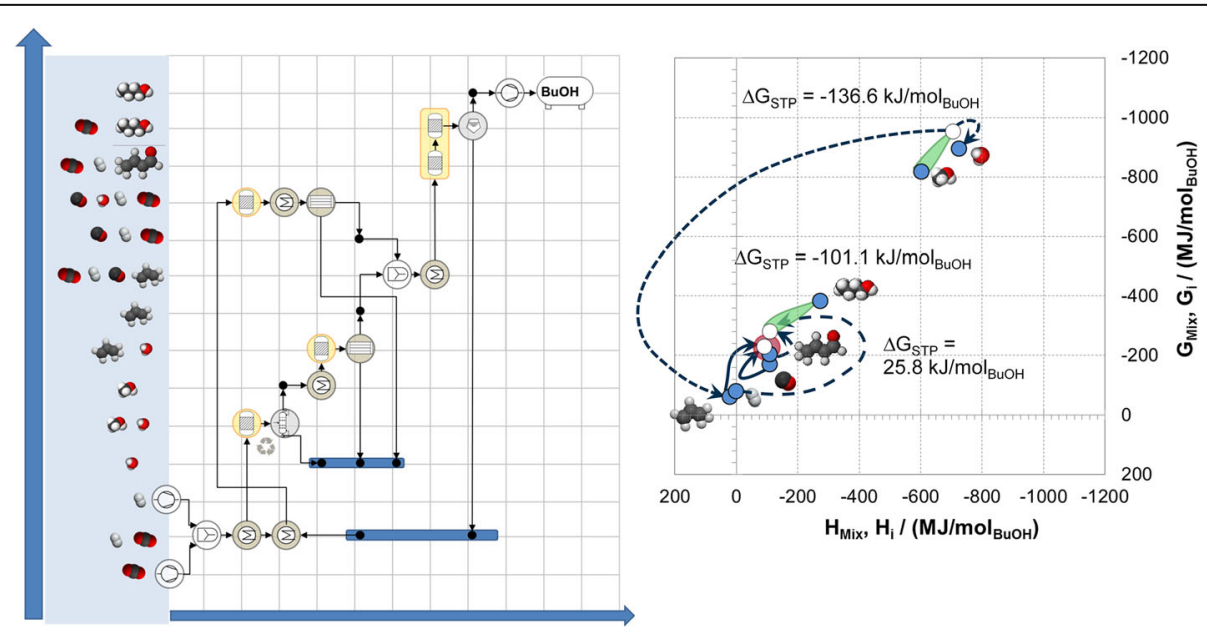

Fig. 13 Principle flow sheet for butanol synthesis from methanol via oxo synthesis of propene and carbon monoxide, in combination with an energy analysis in a G,H-diagram under standard ideal gas state conditions (STP). Symbols see legend in Figs. 8 and 9 


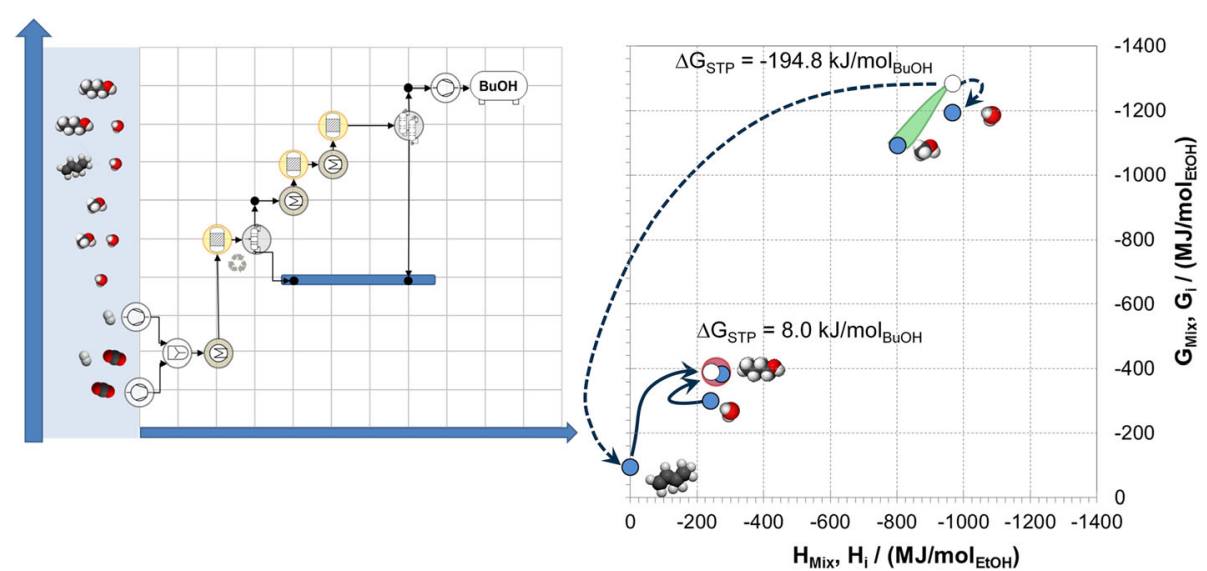

Fig. 14 Principle flow sheet for butanol synthesis from methanol via butene hydration, in combination with an energy analysis in a $\mathrm{G}, \mathrm{H}$-diagram under standard ideal gas state conditions (STP). Symbols see legend in Figs. 8 and 9

proceeds in the liquid phase, activity coefficients calculated by $\mathrm{G}^{\mathrm{E}}$ models such as NRTL or UNIFAC should be used $[28,80]$. A deeper technological assessment must be worked out to determine which pathway achieves the highest yield on butanol with minimal complexity.

The MTO route offers a narrow spectrum of $\mathrm{C}_{2}-\mathrm{C}_{4}$ olefins. With catalyst selection, a focus on propene/butene or ethene/propene mixtures can be set. A hydration step at a farm site would lead to a mixture of various alcohols such as ethanol, 1-propanol, 2-propanol, 1-butanol, and 2butanol. It must be determined if such a mixture can be used directly in potential applications such as internal combustion engines. Otherwise, downstream processing must be implemented. A target production of pure butanol can be achieved by a combination of different chemical reactions. Firstly, a distillation into different fractions of $\mathrm{C}_{2}, \mathrm{C}_{3}$, and $\mathrm{C}_{4}$ alcohols must be performed. The extracted propanol must then be dehydrogenated into propene for the next reaction step. Afterwards, butanol can be gained by means of the aldol condensation of ethanol and by an oxo synthesis of propene. The complexity of this reaction scheme hints at a central production unit.

Considering the production of a liquid at a farm site from $\mathrm{H}_{2}$ and $\mathrm{CO}_{2}$ can be realized at best by methanol synthesis. Subsequently, MTO synthesis is a viable option, in combination with hydration, to achieve a mixture of short-chain alcohols, ranging from ethanol to butanal, and possibly to pentanol.

\section{Socio-economic aspects}

The socio-economic aspects that will be discussed in the next three sections are handling and storage at farm sites, economic factors, and an outlook on environmental evaluation. A further selection of preferred production chains can be found at the end of this paper.

\section{Handling and storage at farm sites}

Social and economic aspects play an important role in the decision of whether to produce locally at farm sites or to undertake production at a central site. This section evaluates fuels with regard to their characteristics that can influence the production decision.

As mentioned above, applicable intermediates concluded from this study are alcohols and DME. The alcohols investigated are methanol, ethanol, butanol, and octanol. These substances are liquids with characteristic odors that are flammable and have a certain risk of explosion at high temperatures, or when mixed with air. DME, for instance, is an extremely flammable gas. Thus, when handling such substances, certain safety protocols must be observed. In the following, these substances are compared according to their health and safety considerations during handling and their characteristics for storage and transport. Tables 5, 6, and 7 contain important information and help with the comparison. The evaluative remarks are an initial attempt to evaluate the risk of farm-site production and provide recommendations. In the end, the risk estimation and production decision should be made by an authorized assessor.

\section{Health risks}

All substances evaluated in this study pose acute and chronic health risks. People can be exposed to them by inhalation, ingestion, and through the skin. In particular, inhalation and direct skin contact may be relevant for workers on the farm, as they could be exposed to the vapor or liquid. Although the substances do not have carcinogenic potential, they can cause irritation to the eyes, skin, and respiratory system; see [43]. Furthermore, DME can create cold fog when leaking, which may cause frostbite. Accumulation of the gas in lowered spaces 
Table 5 Substance characteristics relevant for health from the $[43,44]$

\begin{tabular}{|c|c|c|c|c|c|}
\hline & Methanol & Ethanol & 1-Butanol & 1-Octanol & DME \\
\hline Health risks & \multicolumn{5}{|c|}{ Acute and chronic, no carcinogen potential, harmful if inhaled and swallowed } \\
\hline Effect on central nervous system & $\checkmark$ & $\checkmark$ & $\checkmark$ & $\begin{array}{l}\text { - Possible effect but no } \\
\text { sufficient data }\end{array}$ & $\checkmark$ \\
\hline $\begin{array}{l}\text { Irritation of skin, eyes and respiratory } \\
\text { system }\end{array}$ & $\checkmark$ & $\checkmark$ & $\checkmark$ & $\checkmark$ & $\checkmark$ \\
\hline Other effects & Risk of blindness & - & - & - & $\begin{array}{l}\text { Contact with cold fog can cause } \\
\text { frostbites }\end{array}$ \\
\hline Critical work place value $\left(\mathrm{ml} / \mathrm{m}^{3} ; \mathrm{mg} / \mathrm{m}^{3}\right)$ & $200 ; 270$ & $200 ; 380$ & $100 ; 210$ & $20 ; 106$ & n.s. \\
\hline
\end{tabular}

may in turn cause a shortage of oxygen, which poses the risk of suffocation; see [44].

One serious health risk is the effect of all of the substances on the central nervous system, whereby inhalation can cause confusion, fatigue, headache, and lack of concentration and can even cause unconsciousness in the case of methanol, ethanol, and DME. Methanol has especially serious potential consequences on health. Direct and/or delayed effects include blindness [44] and the potential of death when being exposed to a high concentration of the vapors for several hours because of unconsciousness (>5000 ppm) [42]. The "Institut für Arbeitsschutz der Deutschen Gesetzlichen Unfallversicherung" (IFA) reports blurred vision and/or headaches as the most common disorders after a longer period of exposure in the workplace of approximately $1000 \mathrm{ppm}$ on average [43]. Headaches were also reported for shorter periods. A notable aspect may be that methanol in the air is difficult to smell at concentrations below $2000 \mathrm{ppm}\left(1500 \mathrm{mg} / \mathrm{m}^{3}\right)$ [7]. As the critical workplace value is only $270 \mathrm{mg} / \mathrm{m}^{3}$, it may be difficult to recognize exceedance of this. In general, the critical values allowed in the work place decrease the longer the carbon chain in the alcohol molecule is, resulting in lower amounts of, e.g., butanol and octanol being more irritating compared to methanol and ethanol. Of the alcohols, ethanol is the least toxic (for critical workplace values, compare Table 4). In general, risk estimation is difficult, as critical values and effects are not known to the full extent for all substances [68]. None of the chosen substances can be excluded though and a safety analysis must be performed at each installation site. An official approving authority should then certify the safety measures taken. With regard to the data shown in Table 5, ethanol and butanol are the most suitable.

\section{Handling and storage}

Apart from the health risk, another aspect that is relevant for storage on farms is the risk of explosion. Under the UN hazard classification, the alcohols are classified under category 3 as flammable liquids. DME is classified under category 2.1 as a flammable gas (see Table 46). In the air, as vapor or combined with incompatible substances, methanol, ethanol, and DME easily form explosive mixtures. Butanol and octanol are only explosive at $29{ }^{\circ} \mathrm{C}$ and $81{ }^{\circ} \mathrm{C}$. Their volatility is medium to low, respectively, while methanol and ethanol are highly volatile. DME is heavier than air. It can form a cold fog that travels along the ground and may ignite from a distance. Indeed, a risk of explosion exists for all of the substances, even though it is very lower for octanol [44].

All substances carry certain risks and require safety regulations, such as the control of critical emission values through the installation of gas sensors and the use of closed, solid gadgets and containers to prevent hazards. Thus, handling and coping with spillages

Table 6 Substance characteristics relevant for storage, transport, and safety requirements; if not specified otherwise, data was taken from the [43]

\begin{tabular}{|c|c|c|c|c|c|}
\hline Substance & Methanol & Ethanol & 1-Butanol & 1-Octanol & DME \\
\hline Molecular formula & $\mathrm{CH}_{4} \mathrm{O}$ & $\mathrm{C}_{2} \mathrm{H}_{6} \mathrm{O}$ & $\mathrm{C}_{4} \mathrm{H}_{10} \mathrm{O}$ & $\mathrm{C}_{8} \mathrm{H}_{18} \mathrm{O}$ & $\mathrm{C}_{2} \mathrm{H}_{6} \mathrm{O}$ \\
\hline Boiling point $\left({ }^{\circ} \mathrm{C}\right)$ & 65 & 78 & 118 & 195 & -24.8 \\
\hline Auto-ignition temperature $\left({ }^{\circ} \mathrm{C}\right)$ & 440 & 400 & 345 & 245 & 240 \\
\hline Explosion limits (vol\%) & $6-50$ & $3.1-27.7$ & $1.4-11.3$ & - & 2.8-24.4 Mol\% \\
\hline Explosion limits $\left(\mathrm{g} / \mathrm{m}^{3}\right)$ & $80-665$ & 59-532 & $43-350$ & - & \\
\hline Volatitlity & high & high & medium & low & - \\
\hline Flash Point $\left({ }^{\circ} \mathrm{C}\right)$ & 9 & 12 & 35 & 84 & -42.2 \\
\hline Solubility in water ( $\mathrm{g} / \mathrm{L}$ at $25^{\circ} \mathrm{C}$ ) [49] & 1000 & 1000 & 68 & 0.54 & n.s. \\
\hline UN hazard class [12] & 3 & 3 & 3 & 3 & 2.1 \\
\hline
\end{tabular}


Table 7 Main results from process analysis for methanol, ethanol, 1-butanol, i-octanol, and DME taken from Schemme et al. [74]. Base case: $4.6 € / \mathrm{kg} \mathrm{H}_{2}, 70 € / \mathrm{t} \mathrm{CO}_{2}$, interst rate: $8 \%$, process steam: $32 € / t$, cooling water: $0.1 € / t$, operating electricity: $9.76 € \mathrm{ct} / \mathrm{kWh}$

\begin{tabular}{llllll}
\hline Substance & Methanol & Ethanol & 1-Butanol & i-Octanol & DME \\
\hline Cost base case/€/IDE & 1.89 & 2.22 & 2.53 & 2.85 & 1.85 \\
Energy demand/MJ/IDE & 62 & 70 & 79 & 86 & 60 \\
Efficiency PTF/\% & 58 & 51 & 46 & 42 & 60 \\
Excess heat/MJ/IDE & 3 & 6 & 9 & 8 & 0 \\
CAPEX/€ & 235 & 432 & 673 & 1137 & 298 \\
\hline
\end{tabular}

requires some expertise. For the prevention of safety hazards, a closed system is suggested with explosionproof electrical equipment and ventilation [43].

Due to their high flammability, the handling and storage of methanol, ethanol, butanol, and DME must follow official explosion protection directions ("ExplosionsschutzRichtlinie"). In order to avoid the risk of fire, one should not use compressed air for handling, filling, or discharging (see [43]. Furthermore, the handling of spillages should be carried out in protective clothing and, for all substances but octanol, with the help of a filter respirator for organic vapors and gases. For the storage of butanol and octanol, it is important to consider that they have an effect on materials such as rubber, some plastics, and coatings. Methanol and DME must be stored in a cool place, while DME must also be kept close to the ground [44]. DME tanks should not be exposed to sunlight and the temperature of the substance should be kept below $52{ }^{\circ} \mathrm{C}$ [57]. Methanol is safely stored at a pressure of 2-7 bar depending on the ambient temperature [54]. The requirements of a fireproof and well-ventilated place, away from incompatible substances, apply to all intermediates [44]. With regard to the data shown in Table 6, butanol and octanol are the most suitable in terms of handling and storage.

\section{Transport}

Handling regulations are also important for transport. It is necessary to consider this aspect when producing intermediates at the farm level. Transport is especially relevant for methanol, ethanol, and, to a certain extent, DME. Methanol is classified in packing group II (medium hazard) and ethanol in between group II/III (medium/low hazard). Verhelst et al. state that methanol, for instance, is easy to handle as it is liquid at room temperature [92]. It only becomes gaseous above its boiling point at $65{ }^{\circ} \mathrm{C}$. The boiling point for other alcohols is even higher, which means that they are likely to remain in liquid form. DME, which is unassigned to a packing group, must be transported in liquid form in low pressure tanks [43]. Pressure tanks must be secured against tipping and handled using a hand truck [57].
Moreover, the transport of DME requires a permit by a local authority (see [43]). In comparison, this makes the transport of DME more expensive and complex than that of the alcohols.

\section{Comparison with other fuels}

If the above-mentioned intermediates are compared to other fuels, such as diesel and gasoline, for instance, methanol and ethanol are similar or even less toxic, lethal doses that are generally higher. Furthermore, none of the substances cause cancer [7]. In particular, methanol has been investigated as an alternative fuel in the literature with concern for its safety aspects. In terms of the risk of fire, methanol takes three times longer to ignite compared to gasoline. It also burns with less smoke and a lower temperature, and is easy to extinguish. Therefore, a fire is less likely to occur and if it does, is less damaging. Even the health hazards are considered to be manageable for laymen [13]. Verhelst et al. came to the conclusion that, on the one hand, the storage of methanol is less safe than that of diesel due to its lower flash point [92]. On the other hand, its storage is considered safer than gasoline. Additionally, the vast expansion of the methanol infrastructure in China and the already successful trial case of using fuel in racing cars in California suggests that methanol can be handled safely [7].

\section{Economic aspects}

Costs are important for an investment decision on a synthesis plant, especially if the investment must come from an individual such as a farmer. The system must be able to produce fuels at a competitive price. In general, if a synthesis plant is built, costs augment with the size of it; the more process steps are included, the higher the equipment costs. Schemme [73] analyzed power-to-fuel production facilities for much larger capacities between 30 and $300 \mathrm{MW}_{\text {th }}$ than for a typically farm size of about $1 \mathrm{MW}_{\text {th }}$. A summary of his results is published in Schemme et al. [74]. Important results for methanol, ethanol, 1-butanol, 1-octanol, and DME are given in Table 7. The comparison shows for example costs between $1.85 € / \mathrm{l}_{\mathrm{DE}}$ (DME) up to $2.85 € / \mathrm{l}_{\mathrm{DE}}$ (i-octanol). These numbers correspond very good to the results of Brynolf et al. [8] with $1.60-2.09 € / \mathrm{l}_{\mathrm{DE}}$. When looking at responsible cost factors, the highest costs in power-tofuel production systems occur for the supply of hydrogen. The share of total costs that can be assigned to the $\mathrm{H}_{2}$ supply is between 70 and $80 \%$. Expenses for $\mathrm{CO}_{2}$ were assumed to be at $70 € / \mathrm{t} \mathrm{CO}_{2}$ for these studies. For economic analyses of power-to-fuel concepts, the system efficiency is also an important criteria. Methanol and DME are the best choice in regard to the data in Table 7. If the cost of power production decreases, while the 
Table 8 Environmental substance characteristics

\begin{tabular}{llllll}
\hline Substance & Methanol & Ethanol & 1-Butanol & 1-Octanol & DME \\
\hline Biodegradability & Yes & Yes & Yes & Yes & Yes, but rather slow \\
Water hazard class & 2 & 1 & 1 & n.a. & 1
\end{tabular}

efficiency and carbon conversion increase, the production costs can be minimized [2].

Following the data from FNR in Germany [91], yields between 12 and $17 \mathrm{~m}^{3}$ bio-methane $/ \mathrm{m}^{3}$ liquid manure can be achieved. In regard to the majority of cattle in Germany, our group assumes $15.6 \mathrm{~m}^{3}$ bio-methane $/ \mathrm{m}^{3}$ liquid manure. Actual prices to remove liquid manure of up to $30 € / \mathrm{m}^{3}$ offer a bonus of nearly $1 € / \mathrm{m}^{3}$ biogas, leading to a bonus of about $450 € / \mathrm{t} \mathrm{CO}_{2}$ if $50 \%$ of carbon were assigned to $\mathrm{CO}_{2}$.

It must be stated that the specific cost for a smallscale synthesis plant will increase related to the data of Schemme et al. [74] presented partly in Table 7. The average size of biogas plants in Germany at present corresponds to $500 \mathrm{~kW}_{\mathrm{e}}$ electrical output of a combined heat and power unit (CHP). In a series of publications, the impact of biogas plant size on the overall economic performance has been investigated by the Department of Mechanical Engineering at the University of Alberta [34, $51,78]$. Searcy et al. describe the cost optimal plant size to be a trade-off between the declining capital and operational expenditures on the one hand and increasing costs for feedstock transport on the other hand, as the plant scales increase [78]. In comparison, this approach favors plant sizes of around $200 \mathrm{MW}_{\mathrm{e}}$ and more, which is the size at which specific capital expenditure reduction stagnates [78]. The specific cost optimal size is then dependent on the geographical distribution of different types of feedstock [78]. While these considerations are of importance for future operators of biogas plants, the evaluation of optimal plant size will not be subject of the succeeding analyses, but rather the current conditions are taken into account. Finally, this size corresponds well with the process calculation of Schemme et al. [74].

For a small unit with $500 \mathrm{~kW}_{\mathrm{e}}$, it is more important to choose the simplest molecule for synthesis and for transport. From this perspective, methanol is the first choice. Finally, a detailed techno-economic analysis for this application is lacking and will be performed as a next step.

\section{Environmental evaluation}

The intermediates evaluated in this study have environmental impacts when they are released into the environment. These characteristics should be considered for handling and storage, aside from the above-mentioned health and safety issues. Yet, the intermediates also affect the environment during their production phase. Both aspects should therefore be taken into account when evaluating farm-site production. In this section, only environmental aspects of fuel synthesis, storage, and transport were discussed. A broader approach can consider aspects of waste water cleaning from fermentation and synthesis. Firstly, it is assumed that such a cleaning already exists between fermentation and the gas engine. Additionally, the digestate will be processed to avoid negative impacts on environment. Both items are under research and form the content of a subsequent paper.

The environmental substance characteristics are summarized in Table 6. Methanol is completely soluble in water, but causes water pollution. Therefore, it is classified in WGK $2^{1}$; see the German Environment Agency [90]. Ethanol, butanol, and DME are also soluble in water, although their water pollution hazard is lower (WGK 1). Octanol shows a very poor solubility in water (see [43]. Yet, its release into the environment should be avoided, as it especially harms aquatic life (see [44]. The alcohols investigated are readily biodegradable, whereas DME's biodegradation is fairly slow, as reported by [49]. With regard to the water hazard class shown in Table 8 , ethanol to octanol is better to use than methanol.

Figure 15 shows the process chain, including all production steps, from the raw materials to the fuel that can cause environmental impacts. The figure includes the following impact factors: the production and pretreatment of biomass for the fermentation process (which is negligible for liquid manure), the production of hydrogen and storage, the gas separation process, and the potential fabrication and operation of the plant sites. The production steps require energy, e.g., the gas separation process and the production of hydrogen by the electrolyzer. The fabrication of plant sites may be negligible for $\mathrm{CO}_{2}$ production. Biogas upgrading is already carried out at several biogas plants [24]. Moreover, there is already a large existing infrastructure of biogas fermentation plants in Germany (9331 plants, as of 2017), as reported by Fachverband Biogas [25]. This is supported by Mezzullo et al. who note that emissions from plant construction matter just once in the lifetime of the plant, whereas emissions due to plant utilization are reoccurring [58].

An environmental analysis usually gives insight into airborne emissions. For a holistic environmental

${ }^{1}$ Water hazard class: WGK 1 = low, WGK 2 = clear/existent, WGK $3=$ high https://webrigoletto.uba.de/rigoletto/public/welcome.do $(07.02 .2019)$ 


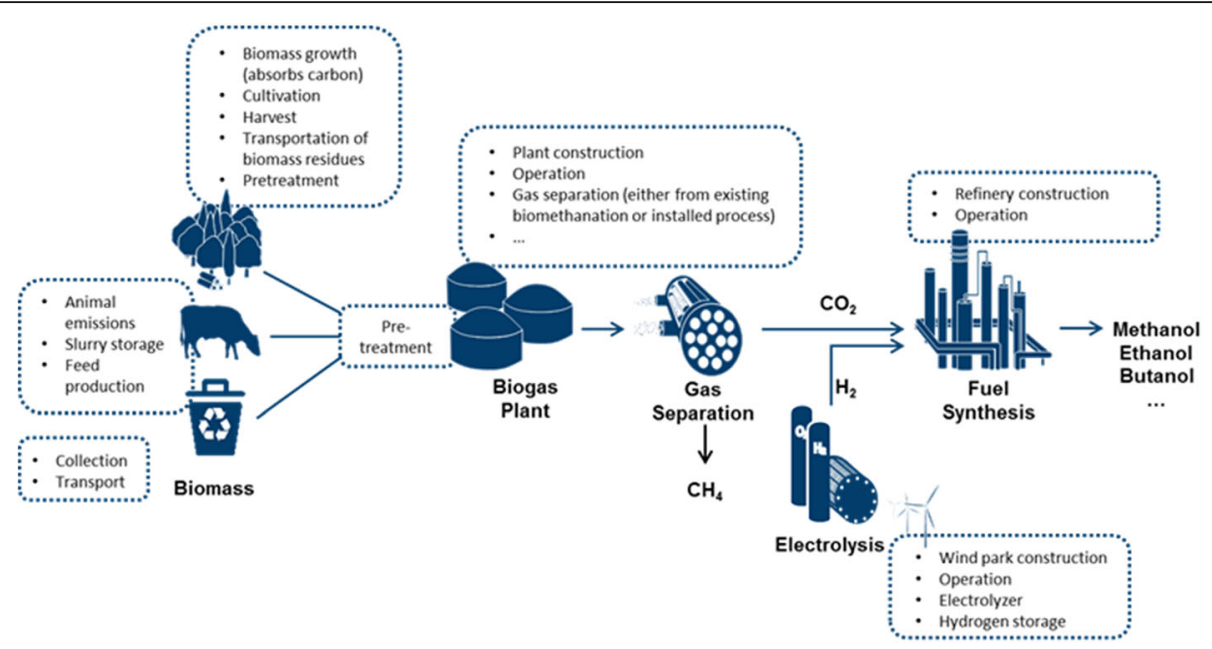

Fig. 15 Production chain with considerable steps that can cause an environmental impact for local fuel production

assessment, the effects on soil and water should also be taken into account. During the production chain, coproducts occur, such as digestate from the fermentation that can be reused as fertilizer. The biomass input from the fermentation process absorbs carbon $/ \mathrm{CO}_{2}$ while growing and therefore is a carbon sink [58]. As mentioned when evaluating biomass as an energy carrier, one should consider not only its $\mathrm{CO}_{2}$ balance but also other environmental aspects, such as the protection of soil, water, and the countryside [55]. In order to consider the relevant environmental considerations in detail, the process technology must be analyzed and a life cycle assessment (LCA) should be performed to give deeper insights into farm-site production.

A first LCA modeling of a power-to-fuel methanol production process according to Fig. 15 showed interesting results, see Eggemann et al. [21]. The analysis considered exclusively residues, namely liquid manure and residues from feed processing, as feedstock and did not account for capital goods. Results showed that credit from co-products like energy and fertilizer made an important contribution in the system's emission savings. Negative emissions, i.e., emission savings of $-3.57 \mathrm{~kg} \mathrm{CO} 2$ eq. for the production of $1 \mathrm{~kg}$ of methanol, were achieved. In comparison, conventional methanol production had emissions of $0.74 \mathrm{~kg} \mathrm{CO}_{2}$ equivalent. The innovative system also performed better in most of the other impact categories that were investigated and showed emission savings in almost all of them (for more details see Table 9). Only in the case of $\mathrm{SO}_{2}$ emissions, the system was more polluting. A more detailed paper about the analysis will be published in future.

\section{Evaluative remarks}

Safety aspects can be decisive as to which intermediates and which fuel can be produced and stored. Alongside production, storage and transport issues play an important role. With regard to mass transport, liquids offer a higher power density in relation to gases. Liquefied gases such as liquid petroleum gas (LPG), DME, liquid natural gas (LNG, and liquid hydrogen (LH2) bear the effort of the implementation of a refrigeration plant, which seems to be too costly and complex for a small farm site.

Even though methanol can cause health issues, there has been sufficient production and usage of methanol as an alternative fuel to provide handling guidelines. In fact, methanol is one of the most produced chemicals in the world (60 million tonnes in 2012). It is used in a wide range of processes in the chemical industry, as well as for bulk chemicals such as formaldehyde and formic acid [33]. Furthermore, several studies have come to the conclusion that the handling risk is manageable [7, 13, 92]. Compared to diesel and gasoline, the health hazards for methanol and ethanol are similar or lower. Environmental hazards exist for all intermediates though. In summary, alcohols with a longer carbon chain in the alcohol molecule

Table 9 LCA modeling results; climate change (GHG), acidification potential (terrestrial) (AP), fossil depletion (FD), photochemical ozone formation (POF), human toxicity (HT), stratospheric ozone depletion $(\mathrm{ODP})$, eutrophication potential (EP)

\begin{tabular}{|c|c|c|}
\hline Impact categories* & $\begin{array}{l}\text { Innovative } \\
\text { power-to-fuel system }\end{array}$ & $\begin{array}{l}\text { Conventional } \\
\text { system }\end{array}$ \\
\hline $\mathrm{GHG}[\mathrm{kg} \mathrm{CO} 2$ eq. $]$ & -3.570 & 0.735 \\
\hline FD [kg oil eq.] & -0.841 & 0.789 \\
\hline EP freshwater [kg P eq.] & $-2.02 \mathrm{E}-03$ & $9.66 \mathrm{E}-05$ \\
\hline EP marine [kg $\mathrm{N}$ eq.] & $-1.58 \mathrm{E}-04$ & $1.68 \mathrm{E}-03$ \\
\hline AP [kg SO 2 eq.] & $8.33 \mathrm{E}-03$ & 1.49E-07 \\
\hline HT [kg 1,4-DB eq.] & -2.044 & 0.000 \\
\hline POF [kg NO${ }_{x}$ eq.] & 0.103 & 0.123 \\
\hline ODP [kg CFC-11 eq.] & $-2.06 \mathrm{E}-05$ & $1.73 \mathrm{E}-03$ \\
\hline
\end{tabular}


bear less risk of explosion. Transport hazards for all of them are medium to low. The transport of DME, however, requires more effort. From a convenience point of view, it may be easier to transport farm-site methanol to large production sites and centrally produce DME.

As there are other emissions that occur on a farm, farm-site production activities should take that into account. A fuel production site requires safety regulations and a storage concept. It is also important that the fuel production system is closed and at a safe distance from high temperatures or explosives. As long as safety regulations are met and the farm can guarantee safe storage and transport, farm-site production for all intermediates can be considered. However, it depends on the right equipment and acceptance by farm owners. In the end, a safety concept must be permitted by the designated authorities.

\section{Conclusions}

Among other possibilities, the production of liquid energy carriers from carbon dioxide and hydrogen can contribute to the sustainability of future energy systems. On one side, the source of hydrogen must be renewable, e.g., produced via water electrolysis using wind or solar electricity. On the other side, the production routes shall not be considered as a possibility to justify the continued operation of fossil-based carbon dioxide emitters, such as coal power plants. In this respect, the carbon dioxide content of the biogas produced in farm sites offers a biogenic carbon dioxide source complementing the renewable nature of the synthetic liquid fuels to be produced.

In order to consider all techno- and socio-economic effects of the farm-site production of synthetic fuels, a deep analysis was performed. The proposed concept foresees the local and distributed small-scale production of a liquid intermediate fuel with elevated power density. This liquid fuel or fuel mixture should be transported to a central site where it is upgraded to a certified fuel.

Firstly, a diesel-like fuel was preferred, leading to substances such as 1-octanol or an $\mathrm{OME}_{3-5}$ mixture. The thermodynamic analysis clearly showed that a syngas pre-processing to convert $\mathrm{CO}_{2}$ into $\mathrm{CO}$ would be better performed by a water-gas shift reactor than by dry reforming. Further on, direct synthesis is most often not possible. This is the reason why synthesis of $\mathrm{OME}_{3-5}$ is so complex. Subsequently, process analyses identified the most common route for $\mathrm{OME}_{3-5}$ as being less suitable for implementation on farm sites due to its huge number of intermediates and complex separation tasks.

Considering an optional cut between the decentralized synthesis of an intermediate at the farm site and centralized fuel synthesis, methanol is definitely the preferred species in the case of $\mathrm{OME}_{3-5}$ synthesis. This is caused by the junction of parallel synthesis pathways for trioxane and methylal forming the desired product $\mathrm{OME}_{\mathrm{x}}$ in a final step. Therefore, $\mathrm{OME}_{3-5}$ was considered for process optimization at a central site only. In the case of alcohol synthesis, methanol, ethanol, and butanol are applicable intermediates. DME can only be chosen with a modification of the synthesis pathway. Nevertheless, both process chains require a large amount of intermediate chemical reaction steps and, for some cases, fairly complex and extensive separation processes.

Process optimization was based on a combination of a Gibbs energy analysis with a visual method identifying the number of chemical reaction steps and the effort for component separation by counting the required unit operations. Finally, a route via (a) methanol synthesis from hydrogen and carbon dioxide with water separation at the agricultural site and subsequent steps; (b) methanol-to-olefins; (c) hydration of olefins to alcohols; (d) distillation; and (e) downstream processing for the various alcohols to fuel products at a centralized site seems to be very attractive. A viable option is the realization of steps (b) to (c) at farm sites if the complexity of the latter process units can be reduced.

Handling and safety aspects play an important role in deciding on an intermediate fuel that is suitable for farm-site production. Energy carriers that are liquid at standard conditions are most suitable due to their higher energy densities in relation to gases. Liquefied gases such as LPG, DME, LNG, and $\mathrm{LH}_{2}$ bear the effort of the implementation of a refrigeration plant and/or pressurized tanks that seems to be too costly and complex for a small farm site. Even though methanol can cause health issues, there has been sufficient experience in the production and usage of it as an alternative fuel to provide handling guidelines. Compared to diesel and gasoline, health hazards for methanol and ethanol are similar or lower. Environmental hazards also exist for all intermediates. In summary, alcohols with a longer carbon chain in the molecule bear less risk of explosion. Transport hazards for all of them are medium to low.

The fact that other emissions occur on a farm should also be taken into account when considering farm-site production. A fuel production site requires safety regulations and a storage concept. It is also important that the fuel production system is closed and at a safe distance from high temperature or explosives. As long as safety regulations are met and the farm can guarantee safe storage and transport, farmsite production for all intermediates can be considered. However, it depends on the right equipment and acceptance by farm owners. In the end, a safety concept must be permitted by the designated authorities. Additionally, an extensive risk assessment would be a valuable contribution to the scientific literature. 


\section{Abbreviations}

$\dot{m}_{\text {Fuel: }}$ Mass flow fuel in $\mathrm{kg} / \mathrm{h}$; $\dot{m}_{\mathrm{H} 2}$ : Mass flow hydrogen in $\mathrm{kg} / \mathrm{h} ; \Delta_{\mathrm{R}} \mathrm{H}^{0}$ : Heat of reaction in $\mathrm{J} / \mathrm{mol} ; \mathrm{H}_{\mathrm{u}}$, : Lower heating value; $\mathrm{P}_{\mathrm{A}}$ : Power demand auxiliaries; $P_{\mathrm{CO} 2}$ : Power demand $\mathrm{CO}_{2}$ separation; $\eta_{\mathrm{H} 2}$ : Efficiency electrolysis;

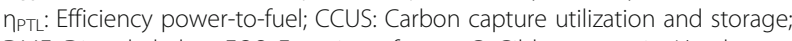
DME: Dimethylether; EOS: Equation of state; G: Gibbs energy in $\mathrm{J} / \mathrm{mol}$;

$G^{E}$ : Gibbs excess energy of a mixture in $\mathrm{J} / \mathrm{mol}^{\prime} \mathrm{G}_{\mathrm{M}}$ : Gibbs energy of a mixture in $\mathrm{J} / \mathrm{mol}$; $\mathrm{H}$ : Enthalpy in $\mathrm{J} / \mathrm{mol}$; IG: Ideal gas; IM: Ideal mixture;

IUPAC: International Union of Pure and Applied Chemistry; j: Indices for species j; KDB: Korea Thermophysical Properties Data Bank; LCA: Life cycle assessment; LH2: Liquid hydrogen; LHV: Lower heating value in J/mol; LNG: Liquid natural gas; LPG: Liquid petroleum gas; MTO: Methanol to olefins; N: Number of species; NIST: National Institute of Standards and Technology; $n_{j}$ : Molar number of moles $\mathrm{j}$ in mol; NRTL: Non-random two liquid, $G^{E}$ model for real mixtures; $\mathrm{OME}_{\mathrm{x}}$ : Polyoxymethylen dimethylether of chain length $\mathrm{x}$; p: Pressure in bar; RG: Real gas; rWGS: Reverse water-gas shift; $\mathrm{S}$ : Entropy in $\mathrm{J} / \mathrm{mol} / \mathrm{k}$; SRK: Soave-Redlich-Kwong, equation of state; STP: Standard pressure and temperature, i.e., 1.013 bar and 298.15 K; T: Temperature in K; UN: United Nations; UNIFAC: Universal Quasichemical Functional Group Activity Coefficients; UOP: Universal Oil Products; $X$ : Growing chain length; $\Delta G_{R}$ : Gibbs energy of reaction in $\mathrm{J} / \mathrm{mol}$; $\mu_{\mathrm{j}}$ : Chemical potential of $\mathrm{j}$ in $\mathrm{J} / \mathrm{mol}$

\section{Acknowledgments}

The authors convey a special thanks to the fuel processing and systems analysis groups at Jülich and all project and cooperation partners. Further thanks are addressed to the members of the JARA Energy seed fund, "Power to Fuel", and its successor-The Competence Center Power to Fuel. JARA (Jülich-Aachen Research Alliance) is an initiative of RWTH Aachen University and the Forschungszentrum Jülich.

\section{Authors' contributions}

$\mathrm{RP}$ is the corresponding author of the paper. He defined the concept of the paper and has written larger parts of the paper. MD contributes mainly to the potential of fuels from biomass and to the basic fuel synthesis design. He also presented the dynamic simulations at UFZ days 2018 in Leipzig. LE has written the chapter socio-economic aspects. STS contributes to this paper with thermodynamic calculations in regard to OME. FS contributes to this paper with thermodynamic calculations and process development in regard to MTO-based processes. The considered synthesis processes for 2-butanol and 2-ethyl-hexanol of this work are based on JBL. Supervision, restructuring, proofreading, and conducting the revision of the study approach were done by SW and RCS. JP contributes to the chemical aspects of different routes towards higher alcohols. RCS guides the ASPEN tool development. DS give his expertise and his guidance to the work of all PhD students involved in this paper. All the authors contributed to the conclusions, the abstract, and the outlook of the study. All authors read and approved the final manuscript.

\section{Authors' information}

$\mathrm{RP}$ is acting director of the newly formed IEK-14 and is heading the department of fuel processing and systems at IEK-3 / -14since 1996. He is also heading the group of future fuels within the department.

MD is PhD student at IEK-14. He works on the implementation of a fuel strategy in future transportation modes.

LE is PhD student at ZC/ IEK-14. Her work is focused on life cycle analysis and socio-economic aspects of fermentation using liquid manure.

STS MD is PhD student at IEK-14. He developed an assessment method for different power-to-fuel processes. His techno-economic analysis comprises alcohols, alkanes and ethers.

FS is PhD student at IEK-14. He is doing technically-oriented path analysis and techno-economic analysis for methanol-to-gasoline and synthesis processes for higher alcohols mainly on the MTO-route.

$J L B$ is PhD student at IEK-14. He works on emission modeling for different transportation modes based on todays and future fuels for the local state of North Rhine Westphalia in Germany. His master work at IEK-14 contained the development of synthesis processes for higher alcohols.

STW is PhD student at IEK-14. He is doing CFD simulations for synthesis reactor design. In parallel he is responsible for $\mathrm{CO}_{2}$ separation processes and for process analysis for methanol and DME synthesis.
JP is heading the group of technical chemistry at IEK-14. He is responsible for the development for heterogeneously catalyzed reaction processes for fuel processing for fuel cells and for fuel synthesis.

RCS is heading the group of APU systems at IEK-3. He is responsible for the development for reactor design for fuel processing for fuel cells and for fuel synthesis and the corresponding systems.

DS is director of IEK-3. He is also doctoral supervisor for all PhD students.

\section{Funding}

The study was funded by the authors, under the umbrella of the Institute of Energy and Climate Research, IEK-14: Electrochemical Process Engineering at the Forschungszentrum Jülich $\mathrm{GmbH}$.

\section{Availability of data and materials}

All data generated or analyzed during this study are included in this published article.

\section{Ethics approval and consent to participate}

Not applicable.

\section{Consent for publication}

Not applicable.

\section{Competing interests}

The authors declare that they have no competing interests.

\section{Author details}

'Forschungszentrum Jülich GmbH, Institute for Energy and Climate Research, IEK-14: Institute of Electrochemical Process Engineering, 52425 Jülich, Germany. ${ }^{2}$ Forschungszentrum Jülich GmbH, ZC: Zukunftscampus, 52425 Jülich, Germany. ${ }^{3}$ Forschungszentrum Jülich $\mathrm{GmbH}$, Institute for Energy and Climate Research, IEK-3: Techno-economic System Analysis, 52425 Jülich, Germany. ${ }^{4}$ Chair for Fuel Cells, RWTH Aachen University, 52072 Aachen, Germany.

Received: 21 May 2019 Accepted: 18 December 2019

Published online: 22 January 2020

\section{References}

1. Albert M, Hahnenstein I, Hasse H, Maurer G (2001) Vapor-liquid and liquidliquid equilibria in binary and ternary mixtures of water, methanol, and methylal. J Chem Eng Data 46:897-903

2. Albrecht FG, König DH, Baucks N, Dietrich R-U (2017) A standardized methodology for the techno-economic evaluation of alternative fuels-a case study. Fuel 194:511-526. https://doi.org/10.1016/j.fuel.2016.12.003

3. Baumgarten C, Bilharz M, Döring U, Eisold A, Friedrich B, Frische T, Gather C, Günther D, Große Wichtrup W, Hofmeier K, Hofmeier M, Jering A, Klatt A, Köder L, Lamfried D, Langner M, Leujak W, Marx M, Matthey A, Mohaupt V, Osiek D, Penn-Bressel G, Palmbeck NO, Pohl M, Rechenberg J, Scheuschner T, Seven J, Ulrich A, Vogel I, Walter AB, Wolter R, Zimmermann A (2018) Umwelt und Landwirtschaft. In: Daten zur Umwelt. Umweltbundesamt, Dessau-Roßlau, p 158

4. Behr A (2000) Ziegler processes. In: Ullmann's Encyclopedia of Industrial Chemistry. Wiley-VCH Verlag GmbH \& Co. KGaA, Weinheim

5. Berndes G, Hoogwijk M, van den Broek R (2003) The contribution of biomass in the future global energy supply: a review of 17 studies. Biomass Bioenergy 25:1-28. https://doi.org/10.1016/s0961-9534(02)00185-x

6. Billig E, Decker M, Benzinger W, Ketelsen F, Pfeifer P, Peters R, Stolten D, Thrän D (2019) Non-fossil $\mathrm{CO}_{2}$ recycling — the technical potential for the present and future utilization for fuels in Germany. J CO2 Util 30:130-141. https://doi.org/10.1016/j.jcou.2019.01.012

7. Bromberg L, Cheng W (2010) Methanol as an alternative transportation fuel in the US: options for sustainable and/or energy-secure transportation. Massachusetts, Cambridge

8. Brynolf S, Taljegard M, Grahn M, Hansson J (2018) Electrofuels for the transport sector: a review of production costs. Renew Sust Energ Rev 81: 1887-1905. https://doi.org/10.1016/j.rser.2017.05.288

9. Burger J (2012) A novel process for the production of diesel fuel additives by hierarchical design. In: Fachbereich Maschinenbau und Verfahrenstechnik. Kaiserslautern, Kaiserslautern, p 137 
10. Burger J, Siegert M, Ströfer E, Hasse H (2010) Poly (oxymethylene) dimethyl ethers as components of tailored diesel fuel: properties, synthesis and purification concepts. Fuel 89:3315-3319. https:/doi.org/10.1016/j.fuel.2010.05.014

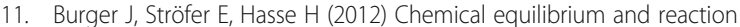
kinetics of the heterogeneously catalyzed formation of poly (oxymethylene) dimethyl ethers from methylal and trioxane. Ind Eng Chem Res 51:1275112761. https://doi.org/10.1021/ie301490q

12. ChemSafetyPRO (2018) Class 1 dangerous goods explosive substances and articles.

13. Cheng WH, Kung HH (1994) Methanol production and use. CRC Press, New York

14. CHERIC Chemical Engineering and Material Research Information Center (2019) Pure Component Properties. CHERIC Chemical Engineering and Material Research Information Center, Gaithersburg

15. Christian DG, Riche AB, Yates NE (2008) Growth, yield and mineral content of Miscanthusxgiganteus grown as a biofuel for 14 successive harvests. Ind Crop Prod 28:320-327. https://doi.org/10.1016/j.indcrop.2008.02.009

16. Dahmen N, Sauer J (2013) Das bioliq -Konzept - Hintergrund und aktueller Stand. KIT, Karlsruhe

17. Decker M, Schorn F, Samsun RC, Peters R, Stolten D (2019) In: Jülich F (ed) Off-grid power-to-fuel systems for a market launch scenario - a technoeconomic assessment, p 32

18. Decker M, Schorn F, Samsun RC, Peters R, Stolten D (2018) Technoeconomic analysis of a stand-alone power-to-liquid concept. UFZ EnergyDays - Energy landscapes of today and tomorrow UFZ, Leipzig

19. Dietrich R-U, Albrecht FG, Maier S, König DH, Estelmann S, Adelung S, Bealu Z, Seitz A (2018) Cost calculations for three different approaches of biofuel production using biomass, electricity and CO2. Biomass Bioenergy 111:165173. https://doi.org/10.1016/j.biombioe.2017.07.006

20. Dry ME (2008) The Fischer-Tropsch synthesis processes. In: G. Ertl HK, F. Schüth, J. Weitkamp (ed) Handbook of heterogeneous catalysis. Wiley-VCH, Weinheim, 2965-2994

21. Eggemann L, Escobar N, Peters R, Burauel P, Stolten D. In A Power-to-Fuel Strategy for Biogas Plants - Life Cycle Assessment of a Small-Scale Fuel Production System, SWEDES - Conference on Sustainable Development of Energy, Water and Environment Systems, Dubrovnik, Croatia, 1.-6.10.2019; International Centre for Sustainable Development of Energy, Water and Environment Systems: Dubrovnik, Croatia, 2019.

22. Ehret O, Bonhoff $\mathrm{K}$ (2015) Hydrogen as a fuel and energy storage: success factors for the German Energiewende. Int J Hydrog Energy 40:5526-5533. https://doi.org/10.1016/j.jjhydene.2015.01.176

23. Ellis C (1934) Prospects of a petroleum chemical industry. Ind Eng Chem 26: 826-836

24. Fachagentur Nachwachsende Rohstoffe e.V. (FNR) (2013) Leitfaden Biogas Von der Gewinnung zur Nutzung. Fachagentur Nachwachsende Rohstoffe. https://mediathek.fnr.de/leitfaden-biogas.htm. Accessed 29 June 2019.

25. Fachverband Biogas Branchenzahlen. (2018). https://www.biogas.org/ edcom/webfvb.nsf/id/de_branchenzahlen. Accessed 29 June 2018.

26. Falbe J (2000) Alcohols, aliphatic. In: Ullmann's Encyclopedia of Industrial Chemistry. Wiley-VCH Verlag GmbH \& Co. KGaA, Weinheim

27. Fougret CM, Hölderich WF (2001) Ethylene hydration over metal phosphates impregnated with phosphoric acid. Appl Catalysis A Gen 207:295-301

28. Fredenslund A, Jones RL, Prausnitz JM (1975) Group-contribution estimation of activity coefficients in nonideal liquid mixtures. AICHE J 21:1086-1199

29. FuelsEurope (ed) (2017) Statistical report 2017. FuelsEurope (ed) FuelsEurope, p 68

30. Gale J, Bradshaw J, Chen Z, Garg A, Gomez D, Rogner H-H, Simbeck D, Williams R, Toth F, Dv V (2005) Sources of $\mathrm{CO}_{2}$. In: Metz B, Davidson O, Coninck Hd, loos M, Meyer $L$ (eds) carbon dioxide capture and storage. Intergovermental Panel on Climate Change, Cambridge, p 431

31. Gassner M, Maréchal F (2012) Thermo-economic optimisation of the polygeneration of synthetic natural gas (SNG), power and heat from lignocellulosic biomass by gasification and methanation. Energy Environ Sci 5:5768. https://doi.org/10.1039/c1ee02867g

32. Gassner M, Maréchal F (2009) Thermo-economic process model for thermochemical production of synthetic natural gas (SNG) from lignocellulosic biomass. Biomass Bioenergy 33:1587-1604. https:/doi.org/10.1016/..biombioe.2009.08.004

33. Gelsenchem Chemical Products $\mathrm{GmbH}$ (n.a.) Methanol

34. Ghafoori E, Flynn PC. Otimizing the size of anaerobic digesters. In CSBE/ SCGAB 2006 Annual Conference, 16-19.7.2006, Canadian Society of Bioengineering: Edmonton, Alberta, 2006; p 39.

35. Goeppert A, Czaun M, Surya Prakash GK, Olah GA (2012) Air as the renewable carbon source of the future: an overview of $\mathrm{CO} 2$ capture from the atmosphere. Energy Environ Sci 5:7833. https://doi.org/10.1039/c2ee21586a
36. Grond L, Schulze P, Holstein J (2013) Systems analyses power to gas. DNV KEMA Energy \& Sustainability, Groningen

37. Grube T, Menzer R, Peters R, Arnold K, Ramesohl S (2006) Verfahrensanalyse der Herstellung flüssiger synthetischer Kraftstoffe auf Biomassebasis. In: VDIBerichte. VDI, Düsseldorf, pp 379-403

38. Hannula I (2015) Co-production of synthetic fuels and district heat from biomass residues, carbon dioxide and electricity: performance and cost analysis. Biomass Bioenergy 74:26-46. https://doi.org/10.1016/j.biombioe.2015.01.006

39. He X (2017) CO2 hydrogenation for ethanol production: a thermodynamic analysis. Int J Oil Gas Coal Eng 5:145. https://doi.org/10.11648/j.ogce. 20170506.14

40. Held M, Tönges Y, Pélerin D, Härtl M, Wachtmeister G, Burger J (2019) On the energetic efficiency of producing polyoxymethylene dimethyl ethers from CO2 using electrical energy. Energy Environ Sci. https://doi.org/10. 1039/c8ee02849d

41. IEA IEA (2018) Key world energy statistics. IEA, Paris

42. IFA, Institut für Arbeitsschutz der Deutschen Gesetzlichen Unfallversicherung (2019) Gestis Stoffdatenbank.

43. Institut für Arbeitsschutz der Deutschen Gesetzlichen Unfallversicherung (IFA) (2019) Gestis Stoffdatenbank. IFA, Berlin

44. International Labor Organization (ILO) (2018) International chemical safety cards (ICSCS). ILO, Genève

45. Jacobi HF, Thrommler M (2014) Technische Möglichkeiten und Potenziale der flexiblen Strombereitstellung aus Biogas. In: Dezentrale flexible Strombereitstellung aus Biogas: Entwicklung, Möglichkeiten und Perspektiven. Deutsches Biomasseforschungszentrum, Berlin

46. Joback KG, Reid RC (1987) Estimation of pure-component properties from group-contributions. Chem Eng Commun 57:233-243. https://doi.org/10. 1080/00986448708960487

47. Kaltschmitt M, Lenz V, Thrän D (2008) Zur energetischen Nutzung von Biomasse in Deutschland - Potenziale, Stand und Perspektiven. Leibnitz Institut für interdisiplinäre Studien, Berlin, p 12

48. Kerdoncuff $P$ (2008) Modellierung und Bewertung von Prozessketten zur Herstellung von Biokraftstoffen der zweiten Generation. Fakultät für Wirtschaftswissenschaften der Universität Karlsruhe, Karlruhe, p 236

49. Kim S, Chen J, Cheng T, Gindulyte A, He J, He S, Li Q, Shoemaker BA, Thiessen PA, Yu B (2018) PubChem 2019 update: improved access to chemical data. Nucleic Acids Res 47:D1102-D1109

50. Krause AOI, Keskinen KI (2008) Etherification. In: HK GE, Schüth F, Weitkamp $\mathrm{J}$ (eds) (ed) Handbook of heterogeneous catalysis. Wiley-VCH, Weinheim, pp 2864-2881

51. Kumar A, Cameron JB, Flynn PC (2003) Biomass power cost and optimum plant size in western Canada. Biomass Bioenergy 24:445-464. https://doi. org/10.1016/s0961-9534(02)00149-6

52. Kvisle S, Fuglerud T, Kolboe S, Olsbye U, Lillerud KP, Vora BV (2008) Methanol to hydrocarbons. In: HK GE, Schüth F, Weitkamp J (eds) (ed) Handbook of heterogeneous catalysis. Wiley-VCH, Weinheim, pp 2950-2965

53. Latscha HP, Kaszmaier U, Klein H (2008) Organische Chemie. Springer, Berlin

54. Liebl J, Beidl C, Maus W (2018) Internationaler Motorenkongress 2018. Springer, Springer

55. Lübbert D (2007) In: Dienste DBW (ed) (ed) CO2-Bilanzen verschiedener Energieträger im Vergleich. Deutscher Bundestag Wissenschafliche Dienste, Berlin, p 32

56. Maurer G (1986) Vapor-liquid equilibrium of formaldehyde-and watercontaining multicomponent mixtures. AlChE J 32:932-948

57. MESA (2018) Specialty Gases \& Equipment. In: Safety Data Sheet Dimethylether

58. Mezzullo WG, McManus MC, Hammond GP (2013) Life cycle assessment of a small-scale anaerobic digestion plant from cattle waste. Appl Energy 102: 657-664. https://doi.org/10.1016/j.apenergy.2012.08.008

59. Minerölwirtschaftverband e.V (2019) Jahresbericht 2018 - Flüssige Kraftstoffe bewegen Deutschland auch 2050. e.V. M (ed). Minerölwirtschaftverband e.V, Berlin

60. Mohseni F (2012) Power to gas : bridging renewable electricity to the transport sector. In: Trita-CHE-Report. KTH Royal Institute of Technology, Stockholm, p v, p 50

61. Mohseni F, Görling M, Alvfors P (2013) The competitiveness of synthetic natural gas as a propellant in the Swedish fuel market. Energy Policy 52 810-818. https://doi.org/10.1016/j.enpol.2012.10.049

62. National Center for Biotechnology Information (2019) 2-Ethylhexanol Names and indentifiers. PubChem (ed). National Center for Biotechnology Information, U.S. National Library of Medicine, Bethesda, MA, U.S.A 
63. National Insitute of Standards and Technology (NIST) (2019) Computational chemistry comparison and benchmark database. NIST, Gaithersburg

64. National Institute of Standards and Technology (NIST) (2015) NIST chemistry WebBook. NIST, Gaithersburg

65. Offermann R, Seidenberger T, Thrän D, Kaltschmitt M, Zinoviev S, Miertus S (2010) Assessment of global bioenergy potentials. Mitig Adapt Strateg Glob Chang 16:103-115. https://doi.org/10.1007/s11027-010-9247-9

66. Parikka M (2004) Global biomass fuel resources. Biomass Bioenergy 27:613620. https://doi.org/10.1016/j.biombioe.2003.07.005

67. Peng D-Y, Robinson DB (1976) A new two-constant equation of state. Ind Eng Chem Fundam 15:59-64

68. Perry RH, Green DW (1997) Perry's chemical engineering handbook. McGraw-Hill, NewYork

69. Peters $R$ (2017) Identification and thermodynamic analysis of reaction pathways of methylal and OME-n formation. Energy 138:1221-1246. https:// doi.org/10.1016/j.energy.2017.07.050

70. Peters R, Baltruweit M, Grube T, Samsun RC, Stolten D (2019) Techno economic analysis of power to gas route. Forschungszentrum Jülich $\mathrm{GmbH}$, Insitute for Energy and Climate Research, Electrochemical Process Engineering, Jülich

71. Robinius M, Otto A, Heuser P, Welder L, Syranidis K, Ryberg D, Grube T, Markewitz P, Peters R, Stolten D (2017) Linking the power and transport sectors_part 1: the principle of sector coupling. Energies 10:956. https:// doi.org/10.3390/en10070956

72. Roth JF (1975) The production of acetic acid. Platinum Metals Rev 19:12-14

73. Schemme S (2019) Techno-ökonomische Bewertung von Verfahren zur Herstellung von Kraftstoffen aus $\mathrm{H}_{2}$ und $\mathrm{CO}_{2}$. In: Mechanical Engineering. RWTH Aachen, Jülich

74. Schemme S, Breuer JL, Köller M, Meschede S, Walman F, Samsun RC, Peters R, Stolten D (2019) H2-based synthetic fuels: a techno-economic comparison of alcohol, ether and hydrocarbon production. Int J Hydrogen Energy 20. https://doi.org/10.1016/j.ijhydene.2019.05.028

75. Schemme S, Breuer JL, Samsun RC, Peters R, Stolten D (2018) Promising catalytic synthesis pathways towards higher alcohols as suitable transport fuels based on $\mathrm{H}_{2}$ and $\mathrm{CO}_{2}$. J CO2 Util 27:223-237. https://doi.org/10.1016/j. jcou.2018.07.013

76. Schemme S, Samsun RC, Peters R, Stolten D (2017) Power-to-fuel as a key to sustainable transport systems - an analysis of diesel fuels produced from CO 2 and renewable electricity. Fuel 205:198-221. https://doi.org/10.1016/j. fuel.2017.05.061

77. Schmitz N, Homberg F, Berje J, Burger J, Hasse H (2015) Chemical equilibrium of the synthesis of poly (oxymethylene) dimethyl ethers from formaldehyde and methanol in aqueous solutions. Ind Eng Chem Res 54: 6409-6417. https://doi.org/10.1021/acs.iecr.5b01148

78. Searcy E, Flynn P (2009) The impact of biomass availability and processing cost on optimum size and processing technology selection. Appl Biochem Biotechnol 154:271-286

79. Silva G, Bozzelli JW (2006) Enthalpies of formation, bond dissociation energies, and molecular structures of the n-aldehydes (acetaldehyde, propanal, butanal, pentanal, hexanal, and heptanal) and their radicals. J Phys Chem A 110:13058-13067

80. Smith JM, van Ness HC (1987) Introduction to chemical engineering thermodynamics. McGraw-Hill, New York

81. Soave G (1993) 20 years of Redlich-Kwong equation of state. Fluid Phase Equilibria 82:345-359. https://doi.org/10.1016/0378-3812(93)87158-W

82. Soave $G$ (1972) Equilibrium constants from a modified Redlich-Kwong equation of state. Chem Eng Sci 27:1197-1203

83. Subramani V, Gangwal SK (2008) A review of recent literature to search for an efficient catalytic process for the conversion of syngas to ethanol. Energy Fuel 22:814-839

84. Szarka N, Scholwin F, Trommler M, Fabian Jacobi H, Eichhorn M, Ortwein A, Thrän D (2013) A novel role for bioenergy: a flexible, demand-oriented power supply. Energy 61:18-26. https://doi.org/10. 1016/j.energy.2012.12.053

85. Teichmann D, Arlt W, Wasserscheid P, Freymann R (2011) A future energy supply based on liquid organic hydrogen carriers (LOHC). Energy Environ Sci 4:2767. https://doi.org/10.1039/c1ee01454d

86. Tremel A, Wasserscheid P, Baldauf M, Hammer T (2015) Techno-economic analysis for the synthesis of liquid and gaseous fuels based on hydrogen production via electrolysis. Int J Hydrog Energy 40:11457-11464. https://doi. org/10.1016/j.jjhydene.2015.01.097
87. Trippe F (2011) Techno-ökonomische Bewertung alternativer Verfahrenskonfigurationen zur Herstellung von Biomass-to-Liquid (BtL) Kraftstoffen und Chemikalien. In: Fakultät für Wirtschaftswissenschaften. KIT, Karlsruhe, p 318

88. Trost T, Horn S, Jentsch M, Sterner M (2016) Erneuerbares Methan: Analyse der $\mathrm{CO}_{2}$-Potenziale für Power-to-Gas Anlagen in Deutschland. In: von Weizsäcker CC, Lindenberger D, Höffler F (eds) (eds) Interdisziplinäre Aspekte der Energiewirtschaft. Springer Fachmedien Wiesbaden, Wiesbaden, pp 295-312

89. Umweltbundesamt (2019) Biogasproduktion aus Gülle und Bioabfall ausbauen. Umweltbundesamt, Dessau

90. Umweltbundesamt (UBA) (2019) Wassergefährdende Stoffe. Umweltbundesamt, Berlin

91. V. FNRe (2019) Biogas. Fachagentur Nachwachsende Rohstoffe e. V, GülzowPrüzen

92. Verhelst S, Turner JWG, Sileghem L, Vancoillie J (2019) Methanol as a fuel for internal combustion engines. Prog Energy Combust Sci 70:43-88. https:// doi.org/10.1016/j.pecs.2018.10.001

93. Victor DG, Zhou D, Ahmed EHM, Dadhich PK, Olivier JGJ, Rogner H-H, Sheikho K, Yamaguchi M (2014) Introductory Chapter. In: Edenhofer O, Pichs-Madruga R, Sokona Y, Farahani E, Kadner S, Seyboth K, Adler A, Baum I, Brunner S, Eickemeier P, Kriemann B, Savolainen J, Schlömer S, von Stechow C, Zwickel T, Minx JC (eds) Climate Change 2014: Mitigation of Climate Change. Contribution of Working Group III to the Fifth Assessment Report of the Intergovernmental Panel on Climate Change. Cambridge University Press, Cambridge, New York

\section{Publisher's Note}

Springer Nature remains neutral with regard to jurisdictional claims in published maps and institutional affiliations.

\section{Ready to submit your research? Choose BMC and benefit from:}

- fast, convenient online submission

- thorough peer review by experienced researchers in your field

- rapid publication on acceptance

- support for research data, including large and complex data types

- gold Open Access which fosters wider collaboration and increased citations

- maximum visibility for your research: over $100 \mathrm{M}$ website views per year

At $\mathrm{BMC}$, research is always in progress.

Learn more biomedcentral.com/submissions 